\title{
How Mobile Augmented Reality Is Applied in Education? A Systematic Literature Review
}

\author{
Fabrício Herpich ${ }^{1}$, Felipe Becker Nunes², Giani Petri ${ }^{3}$, Liane Margarida Rockenbach Tarouco ${ }^{1}$ \\ ${ }^{1}$ Graduate Program in Informatics in Education, Federal University of Rio Grande do Sul (UFRGS), Porto Alegre, Brazil \\ ${ }^{2}$ Antonio Meneghetti Faculty (AMF), Santa Maria, Brazil \\ ${ }^{3}$ Federal University of Santa Maria (UFSM), Santa Maria, Brazil \\ Email: fabricio_herpich@hotmail.com,nunesfb@gmail.com, gpetri@inf.ufsm.br, liane@penta.ufrgs.br
}

How to cite this paper: Herpich, F., Nunes, F. B., Petri, G., \& Tarouco, L. M. R. (2019). How Mobile Augmented Reality Is Applied in Education? A Systematic Literature Review. Creative Education, 10, 1589-1627. https://doi.org/10.4236/ce.2019.107115

Received: May 21, 2019

Accepted: July 22, 2019

Published: July 25, 2019

Copyright (c) 2019 by author(s) and Scientific Research Publishing Inc. This work is licensed under the Creative Commons Attribution-NonCommercial International License (CC BY-NC 4.0). http://creativecommons.org/licenses/by-nc/4.0/ cc) (i) (8) Open Access

\begin{abstract}
Mobile Augmented Reality (MAR) approaches have been applied as an instructional strategy in educational contexts. In this respect, it is important to identify how these approaches have been developed and evaluated with the purpose to identify their quality and benefits. The goal of this article is to identify the state-of-the-art on how the MAR has been used for educational purposes. Therefore, we performed a systematic literature review with a sample of 57 articles. Based on the selected studies, we analysed which knowledge areas the MAR approaches are used in the educational contexts. We also analysed how the approaches have been developed, and evaluated. As a result, we identify that the technical requirements used in the development of the MAR approaches are defined based on the expertise of the development team. Most evaluations are carried out without an appropriate scientific rigor in terms of research design. This shows that there is a need to more consistent and uniform patterns in terms of methods for systematically develop and evaluation of MAR approaches. And, thus, obtain valid results that can be used as a basis for a decision on the application of such approaches and/or their continuous improvement for educational purposes.
\end{abstract}

\section{Keywords}

Augmented Reality, Mobile Learning, Education, Educational Technology

\section{Introduction}

Over the past few years, Information and Communication Technology (ICT) has been introduced in activities in different knowledge areas, helping and even simplifying everyday tasks. Among the areas in which the ICT has contributed, 
there are activities carried out in the educational field, which enables the creation of interactive learning environments, the use of learning objects and the adoption of new technologies applied to education (Guillermo, 2016).

The introduction of technology in education has been used both in a complementary and integral way, giving its users access to didactic and multimedia materials, such as presentations, infographics, images and videos, as well as other pedagogical resources. Different technological solutions have been able to contribute positively to the educational process, which are highlighted by the spread of access to educational resources and an introduction of pedagogical objects in platforms widely used by users, such as educational games (Hainey et al., 2016; Clark et al., 2016; Caballero-Hernández et al., 2017), virtual reality and virtual laboratories (Jong et al., 2013; Heradio et al., 2016; Potkonjak et al., 2016), and augmented reality environments (Kamarainen et al., 2013; Dunleavy \& Dede, 2014; Coimbra et al., 2015).

Among the approaches mentioned above, the augmented reality was recently addressed in the report presented by the New Media Consortium (Becker et al., 2017). In the report, the authors identified and described trends, challenges and developments in technology that can impact planning and decision making in global education. This technology allows to stimulate and construct interactions among users with real and virtual objects. Thus, contributing mainly to the visualization of occurrences that in many cases are invisible makes it capable of fostering students' cognitive abilities (Quintero et al., 2015).

Becker et al. (2017) highlight technologies and practices likely to come into use in their sectors over the next five years (2017-2021). An emphasis is the intensification of the development of augmented reality technologies in 2016, accompanied by the use of mobile learning in the educational contexts for the year 2017, an issue already noted in the 2012 report. In this perspective, currently, there are several studies adopting resources of augmented reality in the educational context (Sommerauer \& Müller, 2014; Cai et al., 2014; Kysela \& Štorková, 2015; Huang et al., 2016; Quintero et al., 2015). In general, findings of these studies demonstrate that multimedia resources provided by augmented reality have the potential to transform the teaching and learning process of students.

A variant of augmented reality technology is the Mobile Augmented Reality (MAR) technology (Chatzopoulos et al., 2017). It has been making inroads in the training and learning domain, as learning approaches can be virtually accessed using the ubiquitous mobile devices, in which, learners can access learning materials and contents anywhere, anytime on their mobile devices (Hanafi et al., 2017). However, O'Shea and Elliott (2016) cited that a limitation in the application of mobile augmented reality in education is that the best practices for the use of these resources in education are still being established, as the years go by and the progress achieved with the robustness of technology and resources related to augmented reality (AR).

During the last years, many case-specific MAR applications have been devel- 
oped with the most of them in the areas of tourism and culture and education while there is currently a huge interest in MAR games (Chatzopoulos et al., 2017). Therefore, it is necessary to identify more uniform patterns in terms of technologies, pedagogical approaches, development and evaluation methodologies and other resources that have been adopted in augmented reality in order to potentiate its contributions when using in educational contexts.

Thus, in order to present the state-of-the-art on how the mobile augmented reality has been used for educational purposes, we conducted a systematic literature review (SLR). The main contribution of this article is the analysis and summary of which knowledge areas are using MAR approaches for education. Moreover, we identified which technical and educational requirements are involved in the development of these approaches (platforms, operating systems, multimedia resources, educational theories and applied methodologies), and how the MAR approaches are being evaluated (evaluation factors, types of studies, target audience, sample size, data collection instruments and data analysis methods). The results of this review may help researchers and teachers in different knowledge areas with an interest in using the MAR as an educational resource to enable more engaging activities for the students as well as a guide for the application in educational practice.

\section{Background}

\subsection{Mobile Augmented Reality}

Augmented reality is the integration of the virtual with the real world, in which computer-based graphic elements are displayed on the screens of the users' technological devices, simultaneously with the elements of the actual environment, in which, the users are (Azuma et al., 2001; Kose et al., 2013; Wang, 2017). In addition, the term "augmented reality" is used in situations where the real scenery is "augmented" through virtual elements (Milgram \& Kishino, 1994). In accordance with Azuma et al. (2001), AR is the insertion of virtual objects in the real world by means of a computational device so that the user interface is used in the real environment, adapted to visualize and manipulate the virtual objects placed in your space.

In accordance with Milgram and Kishino (1994), AR is a middle ground between synthetic and real environments, where the AR complements the real-world, providing to users the idea that virtual and real objects exist together in the same space. Augmented Reality has been recognized as a technology that can assist learners in dealing with real-world targets and tasks with supports from the digital systems (Chittaro \& Ranon, 2007; Chang \& Hwang, 2018).

Augmented reality technologies are attractive since the last decade for they help the users in understanding the real world through the virtual by processing information and showing it in a simple manner (Reyes-Aviles \& Aviles-Cruz, 2018). Azuma (1997) argues that there are three essential characteristics of computational systems with augmented reality: 1) combine virtual elements with the 
real environment; 2) interactive and have its processing in real time, and 3) registered in three dimensions.

Regarding the uses and applications of mobile augmented reality resources, investigations are being performed to help in diverse areas such as entertainment (Fonseca et al., 2016), advertising and marketing (Chang et al., 2014), tourism (Chung et al., 2015), motoring (Rameau et al., 2016), health care (Jamali et al., 2015), training and education (O’Shea et al., 2016), which use MAR approaches to develop interactive and engaging content, offering opportunities to their users to an enriching educational experience.

\subsection{Developing and Evaluating MAR Educational Approaches}

Studies of the development of MAR approaches have been conducted with the aim of contributing to the educational process. According to Radziwill et al. (2015), organizations are about to experience a major shift in their conceptual models-one that will naturally emphasize the virtues of STEAM (Science, Technology, Engineering, Art, and Mathematics). By effectively organizing and promoting rich environments for STEAM learning, we can immediately and purposefully engage in supporting that outcome (Radziwill et al., 2015). In this context, computer simulations have been proved to be effective in teaching difficult concepts to the students, particularly in the STEAM disciplines (Lindgren et al., 2016; Reyes-Aviles \& Aviles-Cruz, 2018). In this respect, Chen and Tsai (2012) contribute stating that although augmented reality technology is not a novelty, its potential in educational applications is currently being explored.

Due to the technological novelty of AR, the issues with regard to its capability of learning supports have been increasingly explored and discussed in educational technology research during the past few years (Cheng, 2018). The use of AR technology could help learners focus on the critical real-world targets with relevant digital information, which would ease their learning load (Hwang et al., 2018). As an educational technology, the potential affordance of augmented reality features consists of multimedia materials that are displayed relative to the real environment (Santos et al., 2014a). Besides, the features of presenting learning information (e.g. texts, videos, audios, and three-dimensional) together in real-time interaction might stimulate learners to learn abstract ideas more than only reading a book (Specht et al., 2011).

In addition, it is growing the combination of these features with emerging educational technologies such as mobile devices (Joo-Nagata et al., 2017; Frank \& Kapila, 2017), educational games (Zarzuela et al., 2013; Furió et al., 2013a), infographics (Mahmoudi et al., 2017), among others. Augmented reality emerges as a potential perspective to complement educational applications as it makes it possible to explore its virtual resources for educational bias by adding to these educational solutions the scale presentation of three-dimensional virtual elements. In this respect, Santos et al. (2014b) describe that augmented reality offers a differentiated set of characteristics, and, thus, can be used differently from 
other existing technologies in the educational field, some of these characteristics being the insertion of notes in the real world and contextualized visualization.

In order to develop educational mobile augmented reality approaches, it is important that some technical and educational requirements be defined, such as augmented reality Software Development Kit (SDK) (Santos et al., 2014b), recognition and tracking features (Amin \& Govilkar, 2015), multimedia pedagogical resources (Yen et al., 2013), and a support of educational theory (Wang, 2017).

Developing educational resources with AR on mobile technologies bring up the need to choose a platform or development framework that attends the requirements required by the project (Amin \& Govilkar, 2015; Rautenbach et al., 2016). Currently, there is a range of tools that allow the development of educational resources in AR, for example, Aurasma (HP Reveal) (2017), Vuforia (2018), and Wikitude (2018). Each tool has different features and functionalities that must be observed in order to meet the application development requirements.

The choice of an Augmented Reality SDK facilitates many components within the mobile augmented reality application: recognition, tracking, and content rendering. An array of tools is provided to developers through $\mathrm{SDK}$, required to recognize, track and render AR application in the most efficient manner (Amin \& Govilkar, 2015). Therefore, the features of each mobile augmented reality development platform must be observed within these three categories, for example, the recognition ways: textual, markers, multi targets, and 3D objects; the tracking ways: cameras and the global positioning system; and rendering content: images, videos, audios, 3D objects, and animations.

The technologies used always need to depend on the pedagogical goals, the needs of the educational application and the target audience. Regarding the design of appropriate strategies that can be applied to the creation of more effective augmented reality learning experiences, Santos et al. (2014b) cited that the mobile augmented reality applications should enable exploration, promote collaboration, and ensure immersion.

Besides the educational and technological requirements that should be considered in the development of mobile augmented reality approaches, it is important to evaluate the quality and effectiveness of these approaches when using with educational purposes as an instructional strategy. In this context, typically, evaluation of instructional strategies is conducted through empirical studies (Wohlin et al., 2012; Branch, 2010). The evaluation of mobile augmented reality as an educational approach seeks to verify if the educational technology reaches its goals and expectations of the target audience.

Typically, evaluations are conducted with the application of the treatment with the target audience and then data are collected and interpreted (Branch, 2010). An empirical study can be conducted as a formal experiment, a case study, survey, etc. and, typically, follow a process organized in the steps of scop- 
ing, planning, operation, analysis \& interpretation, and presentation (Wohlin et al., 2012).

The first step (scoping), the assessment goals should be determined and the factors that will be evaluated are assigned. In the next phase (planning), a research design should be defined in accordance with the context of the study. A formal experiment includes control and experimental groups with random allocation of the participants. If the allocation of the participants was not random but the study uses control and experimental groups, a quasi-experiment can be used.

On the other hand, if the study uses only one group of participants but is performed in a systematic manner a non-experimental research design, such as case study, can be used. Studies that are conducted in an unsystematic way, lacking a defined objective and methods can be characterized as ad-hoc.

To achieve the objective defined to the evaluation, a measurement may be conducted (Fenton \& Pfleeger, 1998). Thus, factors to be measured and instruments to systematically collect data from these defined factors are determined. In the operation phase, the treatments (the MAR approach and other activities for comparison) are applied and the data are collected from the target audience. In the phase of analysis, the data collected in the study are interpreted based on the measured factors. Typically, qualitative and/or quantitative data analysis methods may be used, ranging from descriptive statistics to hypothesis tests (Freedman et al., 2007). Lastly, in the presentation phase, the results are documented in reported, typically, in technical reports or research articles.

\section{Related Works}

Analysis of literature for development of this section sought to highlight some important points related to the use of augmented reality resources in mobile devices in education. In line with this analysis, we also highlighted some of the main literature reviews carried out over the past few years by different researchers in order to provide a clear view of the conducted studies and the gaps to be filled currently with this review.

Researches focused on technological aspects have been carried out in order to highlight the particularities involved in the development of these applications with augmented reality features, as well as in the tools and platforms currently available. Amin and Govilkar, (2015) and Rautenbach et al. (2016) present an analysis of the existing platforms for specific purposes of augmented reality. Herpich, Guarese and Tarouco (2017) compared the existing platforms for the development of mobile augmented reality approaches, specifying augmented reality resources which each offers for the construction of educational solutions on mobile devices. Another analysis of the tools can be found in Social Compare (2017), where they are maintained from the precursor platforms of augmented reality to the most current, which are updated by users and developers in a cooperative way and allow a specific view of the tools. An interesting point of view 
was also addressed in the research of Palmarini et al. (2018) about the use of augmented reality features and aspects related to their maintainability, highlighting the discrepancy (fragmentation) of integration between hardware, software and augmented reality solutions.

From the educational perspective, several initiatives have also been explored through literature reviews. Zhu et al. (2014) address the use of augmented reality for healthcare teaching. The augmented reality approaches developed did not have an explicit pedagogical framework. Literature analyses involving the use of augmented reality resources for teaching can also be seen in the study of Bacca et al. (2014), in which, trends, visions for the future and opportunities for future research in augmented reality for educational environments are discussed.

Diegmann et al. (2015) describe as the results of their review that the specific directions of augmented reality approaches are more likely to lead to certain benefits, such as increased motivation. Akçayir and Akçayir (2017) emphasize the results obtained with the literature analysis, that augmented reality approaches promote a better learning performance, in which the problem most identified in the analysed researches is centered in the difficulty of students to use this type of application in a better form to promote learning.

O'Shea and Elliott (2016) conducted an exploratory analysis of available mobile augmented reality approaches for educational purposes, with the intention of evaluating them for their potential and affordances to transform the way education can occur with the use of augmented reality and not just how content can be presented to students that interact with these types of technologies. The rationale presented by the authors consists in the fact that AR has achieved great advances in the robustness of technology, aspect that also converged with the wide dissemination in the use of mobile devices, but emphasize that the practical improvements to the use of these resources in education are still being defined and redefined. So, it is necessary to deepen the affordances that AR has to offer, seeking to highlight the added value that these applications can offer and how best to take advantage of its distinct characteristics to improve learning.

Saidin et al. (2015) describe a review of augmented reality in education, focusing on demonstrating the advantages and resources with potential to transform educational environments. Considering that in the perspective of AR technology, since its conception, seeks to promote a more active, effective and meaningful learning process, unlike other technologies that have emerged for educational purposes, but have created a passive learning process that does not use its resources to promote critical thinking and creation of meaning or metacognition.

Another aspect that Saidin et al. (2015) highlighted is the visualization of content as one of the main characteristics with the potential to expand education. Since AR resources are capable of engaging students in learning processes and helping to improve their visualization skills, a factor that is enhanced by the ability of AR to enable students to be immersed in realistic experiences, creating 
meaning for those who interact more actively.

Analysing the related works we can identify that the augmented reality, in fact, has a potential to be used as an educational strategy. However, these studies do not include a detailed and complete analysis of the use of augmented reality with mobile devices. Thus, the question of how the mobile augmented reality has been applied with educational purposes stays open. This SLR expects to identify how the mobile augmented reality approaches have been developed and evaluated in the last 8 years, focusing on the technical and educational development requirements.

\section{Research Method}

To identify the state-of-the-art on how the mobile augmented reality has been used for educational purposes was conducted a Systematic Literature Review following an adaptation of the process developed by Kitchenham et al. (2010), as illustrated in Figure 1. According to Kitchenham et al. (2010), SLR is an effective way of aggregating knowledge about a topic or research question, once the most reliable evidence comes from aggregating all empirical studies on a particular topic.

Kitchenham et al. (2010) also affirm that the recommended methodology for aggregating empirical studies is a SLR, approach that is present in several current studies, e.g., SLRs on the use of serious games (Calderón \& Ruiz, 2015) and how they are evaluated (Petri \& Gresse von Wangenheim, 2017). A SLR involves a systematic process (Figure 1) to search studies which address a defined research question as well as a systematic presentation and synthesis of the characteristics of the selected studies.

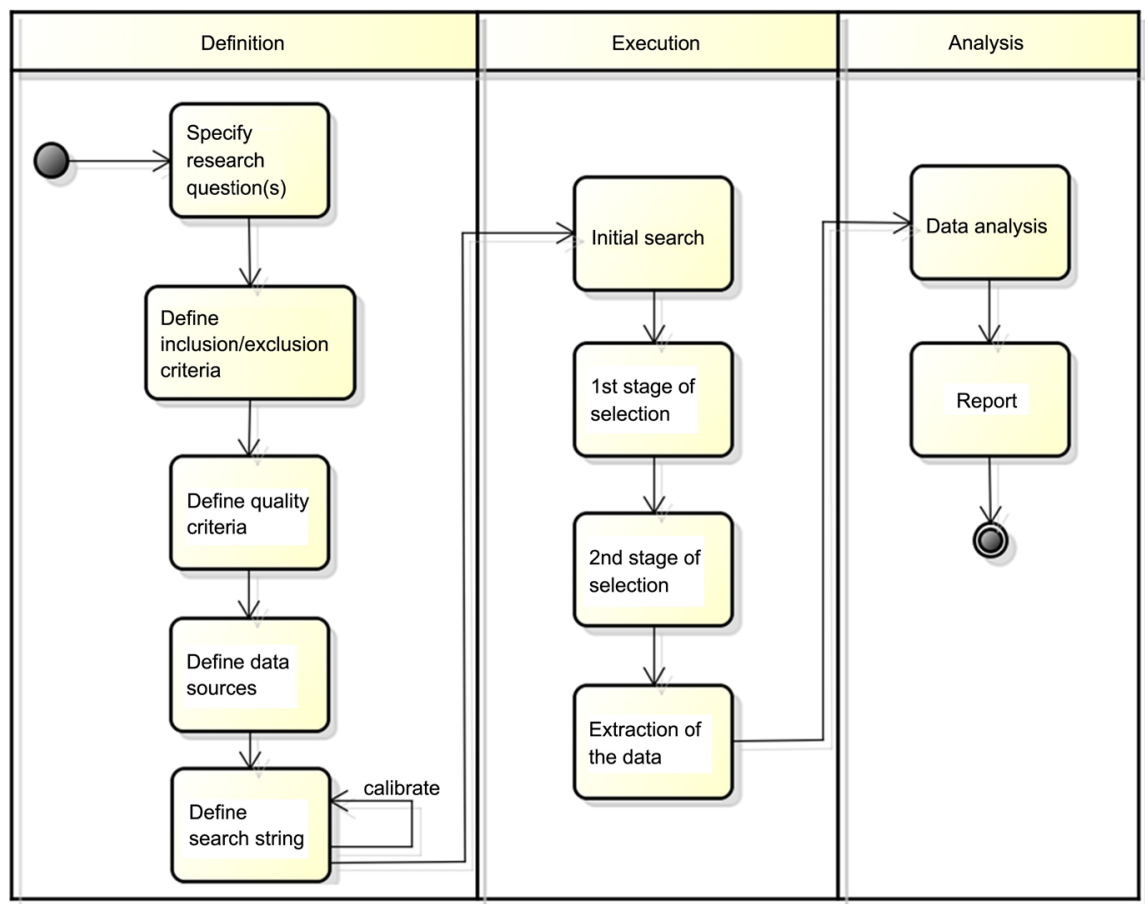

Figure 1. Activity diagram of SLR process (adapted from Kitchenham et al., 2010). 
The SLR procedure is organized in the phases of definition, execution, and analysis (Figure 1). First (Section 5), a protocol for the review is defined, determining a research question, inclusion \& exclusion criteria as well as data sources and the search string. Second, in the execution phase (Section 6), the protocol review is applied in order to search and identify relevant studies, considering the inclusion and exclusion criteria defined in the protocol. Third, in the analysis phase (Sections 6 and 7), the selected studies are analysed and the data are extracted in order to answer the research questions defined and to achieve the objective of this SLR.

\section{Definition of the Systematic Literature Review}

This study aims at the elicitation of the state-of-the-art on how the mobile augmented reality has been used for educational purposes. In accordance with this purpose, we performed an SLR, following the steps defined in Section 4, focusing on the following research questions:

- RQ1: Which knowledge areas the mobile augmented reality approaches used in the educational contexts have been applied?

- RQ2: How the mobile augmented reality approaches used for educational purposes have been developed?

- RQ3: How the mobile augmented reality approaches used for educational purposes have been evaluated?

In accordance with our research objective and questions, inclusion and exclusion criteria for selecting only relevant studies were defined.

Inclusion criteria:

- The study presents augmented reality resources applied in education;

- The study presents results that match the objective defined for the article and the instruments used in the evaluation of augmented reality applied in education;

- The study allows access to augmented reality features through a mobile application or provides a module that enables access via mobile devices;

- The study was written in English; Keywords are present in the structure of the article as a whole;

- The study was published between 2011 and 2018;

- This range of years has been defined with the objective of finding only up-to-date research using technologies developed over the past few years.

Exclusion criteria:

- The study does not address the actual application of augmented reality resources in education, that is, it only has the terms searched in the text of the article;

- The study presents technical reports, or documents in the form of abstracts, presentations, or revisions of secondary literature;

- The study is centered only on theoretical and philosophical aspects (without a definition of technique, application and/or methodology); 
- The study does not present the results clearly and the instruments used in the evaluation of augmented reality applied in education;

- The study was written in a language different of English.

Quality Criteria: As quality criteria we define that, besides to consider the inclusion criteria, the study need provide sufficient information in order to answer our analysis questions, clearly indicating the knowledge area that the MAR approach is applied and its aspects regarding its development and evaluation.

Data Sources and Search String: Data sources have been chosen based on their relevance in the domain of technologies/informatics in education in accordance with the SJR (Scientific Journal Rankings) 2017, including:

- British Journal of Educational Technology;

- Computer Applications in Engineering Education;

- Computers and Education;

- Computers in Human Behavior;

- Creative Education;

- Educational Technology Research and Development;

- IEEE International Symposium on Mixed and Augmented Reality;

- IEEE Transactions on Learning Technologies;

- International Journal of Computer-Supported Collaborative Learning;

- Journal of Computer Assisted Learning;

- Journal of Computers in Education;

- Journal of Educational Technology \& Society;

- Journal of Science Education and Technology.

In order to construct the search string, we first chose to identify the central concepts of this work (e.g., augmented reality, mobile learning and education). In this process, synonyms are also used, as can be seen in Table 1, in order to complement the research carried out.

Using these keywords, the search string has been calibrated and a generic string was defined: ("mixed reality" OR "augmented reality") AND (education OR teaching OR learning) AND (“mobile learning” OR “m-learning” OR “m-learning” OR "mobile device" OR "mobile computing" OR "handheld computer").

\section{Execution of the Review}

The SLR was conducted between October 2017 and July 2018 by the first two authors, Ph.D. candidates, and was reviewed by two senior researchers (third and fourth authors).

In the first step of the research (Step 1), the search string was applied to the selected data sources. As a result of this initial search, we found a total of $296 \mathrm{ar}-$ ticles (Table 2). The specific number of articles for each database is shown in Table 2.

The second step of the research (Step 2) consisted of analysis of the articles selected in Step 1, in which the inclusion and exclusion criteria were used to select the articles for the final analysis of the SLR. This phase consists of reading 
Table 1. Keywords.

\begin{tabular}{cc}
\hline Core Concepts & Synonyms \\
\hline Augmented Reality & Mixed Reality \\
Education & Teaching, Learning \\
Mobile Learning & M-learning, mLearning, Mobile Device, \\
& Mobile Computing, Handheld Computer \\
\hline
\end{tabular}

Table 2. Selected articles in each data source and steps.

\begin{tabular}{cccc}
\hline Data Source & Step 1 & Step 2 & Step 3 \\
\hline Computers and Education & 52 & 23 & 18 \\
Computers in Human Behavior & 48 & 18 & 8 \\
IEEE International Symposium on & & 7 & 1 \\
Mixed and Augmented Reality & 40 & 7 & 2 \\
British Journal of Educational Technology & 32 & 5 & 4 \\
Journal of Computer Assisted Learning & 26 & 12 & 4 \\
IEEE Transactions on Learning Technologies & 18 & 6 & 4 \\
Journal of Science Education and Technology & 17 & 6 & 4 \\
$\begin{array}{c}\text { Computer Applications in Engineering Education } \\
\text { Journal of Educational Technology \& Society }\end{array}$ & 16 & 11 & 6 \\
Educational Technology Research and Development & 12 & 7 & 4 \\
Journal of Computers in Education & 10 & 1 & 1 \\
International Journal of & 5 & 1 & 0 \\
Total & 296 & 106 & 57 \\
Computer-Supported Collaborative Learning & & 2 & 1 \\
Creative Education & 5 & 7 & \\
\hline
\end{tabular}

the titles, abstracts and keywords of the 296 articles that were found in the previous stage, resulting in 106 articles included and 190 excluded.

Finally, in the third step (Step 3), a complete reading of the 106 articles selected in Step 2 was performed, and the inclusion and exclusion criteria were again applied. At the end of Step 3, 49 articles were excluded, and 57 articles were considered for data extraction. After the final selection, the articles were analysed and the data extracted, aiming to answer the research questions and consequently reach the objective of the study.

\section{Data Extraction}

In order to organize and facilitate the process of analysis of the data processed in the SLR, an online table (available in the supplementary material) was created for the sharing of selected articles and their respective Data Items, which are visualized in Table 3. 
Table 3. Data items extracted.

\begin{tabular}{|c|c|c|}
\hline Research Question (RQ) & Data Item (DI) & Description \\
\hline \multirow{4}{*}{$\begin{array}{l}\text { RQ1: Which knowledge areas the } \\
\text { mobile augmented reality } \\
\text { approaches used in the educational } \\
\text { contexts have been applied? }\end{array}$} & Reference & Reference of the study. \\
\hline & Knowledge area & $\begin{array}{l}\text { Knowledge area in which the study was } \\
\text { conducted. }\end{array}$ \\
\hline & $\begin{array}{l}\text { Platforms for } \\
\text { development }\end{array}$ & $\begin{array}{l}\text { Development platforms used in the } \\
\text { development of the augmented reality } \\
\text { approaches. }\end{array}$ \\
\hline & Operating systems & $\begin{array}{l}\text { Operating systems on which augmented } \\
\text { reality education solutions are being } \\
\text { built. }\end{array}$ \\
\hline \multirow{7}{*}{$\begin{array}{l}\text { RQ2: How the mobile augmented } \\
\text { reality approaches used for } \\
\text { educational purposes } \\
\text { have been developed? }\end{array}$} & Educational theories & $\begin{array}{l}\text { Educational theories to provide Mobile } \\
\text { Learning in augmented reality } \\
\text { approaches. }\end{array}$ \\
\hline & $\begin{array}{l}\text { Multimedia } \\
\text { resources }\end{array}$ & $\begin{array}{l}\text { Educational multimedia resources } \\
\text { presented in augmented reality and } \\
\text { used in AR approaches to promote } \\
\text { education. }\end{array}$ \\
\hline & $\begin{array}{l}\text { Methodology of } \\
\text { development }\end{array}$ & $\begin{array}{l}\text { Methodology used for the development } \\
\text { of the augmented reality approach for } \\
\text { education. }\end{array}$ \\
\hline & Quality factors & Factors used in evaluations. \\
\hline & Type of study & Type of study defined for evaluation. \\
\hline & Target audience & Target audience selected. \\
\hline & Sample size & $\begin{array}{l}\text { Number of participants involved in the } \\
\text { evaluation. }\end{array}$ \\
\hline \multirow[t]{4}{*}{$\begin{array}{l}\text { RQ3: How the mobile augmented } \\
\text { reality approaches used for } \\
\text { educational purposes } \\
\text { have been evaluated? }\end{array}$} & Evaluation approach & $\begin{array}{l}\text { It used some model/method/ } \\
\text { framework/scale that was developed } \\
\text { specifically to evaluate augmented } \\
\text { reality with mobile devices. }\end{array}$ \\
\hline & $\begin{array}{l}\text { Data collection } \\
\text { instrument }\end{array}$ & $\begin{array}{l}\text { Instruments used to collect data of } \\
\text { evaluation. }\end{array}$ \\
\hline & $\begin{array}{l}\text { Methods of data } \\
\text { analysis }\end{array}$ & $\begin{array}{l}\text { Methods used to analyse the data } \\
\text { collected in the evaluation. }\end{array}$ \\
\hline & Main results & $\begin{array}{l}\text { Synthesis of the main results obtained } \\
\text { in the evaluation of the study. }\end{array}$ \\
\hline
\end{tabular}

In total, we identified 57 articles describing approaches to use the mobile augmented reality in education. Although we considered the last 8 years (2011-2018) in our review, most of the articles are published from 2013. This shows that the interest in the application of mobile augmented reality in education has been growing over the past few years, as can be seen in the year 2016, which obtained the highest number of published articles (14). In the other years, the distribution was of 2011 and 2012 (both with one article), 2014 (11 articles), 2015 (5 articles), 2017 (12 articles) and 2018 (6 articles).

This section demonstrates in a clear and detailed way the results obtained in 
each of the defined research questions, presenting an explanation of the data analysed, and a detailed discussion in Section 9. In order to present our findings, we analyse the research questions separately.

- RQ1: Which knowledge areas the mobile augmented reality approaches used in the educational contexts have been applied?

In order to answer this question, we analysed the selected articles in terms of knowledge areas in which the approaches of augmented reality and their resources have been applied to education.

Analysing the selected studies, it was possible to classify 17 different knowledge areas that used mobile augmented reality in their research to provide access to teaching materials, as well as to contribute to the teaching-learning process of students (Table 4). The selected studies presented a great diversity of teaching areas in which the MAR approaches have been applied. In order to provide a categorical view, we chose to adopt the STEAM terminology (previously mentioned in Section 2.1). The aim of this categorization is to present studies grouped in large areas of teaching, which facilitates researchers to search for works developed in one of the five major areas defined in STEAM.

- RQ2: How the mobile augmented reality approaches used for educational purposes have been developed?

In order to answer this question, we analysed the selected articles in terms of platforms, operating systems, educational theories/strategies, methodological procedures and multimedia resources that are being used in the development and use of educational approaches on mobile devices.

Regarding the platforms (SDKs, Frameworks, and Plugins) used for the development of augmented reality approaches, we found some tools in the literature that implemented their educational resources using general software development tools or languages: Unity 3D (5 studies), XCode (5 studies), Java (3 studies), iPhone SDK (3 studies), Android SDK (2 studies), Game Studio A8, Microsoft Visual Studio, and Mobile Media API; AR SDK or Frameworks: ARToolKitPlus (4 studies), Vuforia (3 studies), AR-Media, OpenCV, ZXing QR-code, and Wikitude; AR content platforms: Layar (5 studies), Metaio (4 studies), Junaio (4 studies), Aurasma (3 studies), SIO2 (3 studies), ARIS Platform (2 studies), Mixare (2 studies), ARLearn, Artlantis, FreshAir, and GLUEPS-AR. Others 18 articles did not specify the tools they used.

The large diversity and number of platforms available currently can be observed in this result, with a special emphasis on the Unity 3D, Layar, XCode and Metaio platforms. This finding demonstrates the rise in the technological development of mobile augmented reality approaches that have occurred over the past few years, where various alternatives to support the creation of approaches with augmented reality features are currently available. Some articles have also specified the tools used to create multimedia resources and pedagogical content presented in mobile augmented reality approaches: Blender 3D (4 studies), Google 
Table 4. Selected articles per knowledge area.

\begin{tabular}{|c|c|c|c|c|c|}
\hline References & Science & Technology & Engineering & Art & Math \\
\hline Akçayir et al. (2016) & $\mathrm{x}$ & - & - & - & - \\
\hline Botella et al. (2011) & $\mathrm{X}$ & - & - & - & - \\
\hline Bressler and Bodzin (2013) & $\mathrm{x}$ & - & - & - & - \\
\hline Bressler and Bodzin (2016) & $\mathrm{x}$ & - & - & - & - \\
\hline Chang and Hwang (2018) & $\mathrm{x}$ & - & - & - & - \\
\hline Chang et al. (2014) & - & - & - & $\mathrm{X}$ & - \\
\hline Chang et al. (2015) & - & - & - & $\mathrm{X}$ & - \\
\hline Chang et al. (2013) & $\mathrm{x}$ & - & - & - & - \\
\hline Cheng (2018) & - & - & - & $\mathrm{X}$ & - \\
\hline Cheng and Tsai (2014) & - & - & - & $\mathrm{X}$ & - \\
\hline Cheng and Tsai (2016) & - & - & - & $\mathrm{X}$ & - \\
\hline Chiang et al. (2014a) & $\mathrm{x}$ & - & - & - & - \\
\hline Chiang et al. (2014b) & $\mathrm{X}$ & - & - & 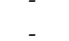 & 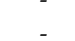 \\
\hline Cubillo et al. (2015) & - & - & $\mathrm{x}$ & - & - \\
\hline Delello (2014) & $\mathrm{x}$ & - & - & - & - \\
\hline Echeverría et al. (2012) & $\mathrm{X}$ & - & - & - & - \\
\hline Fonseca et al. (2014) & - & - & $\mathrm{x}$ & - & - \\
\hline Fonseca et al. (2016) & - & - & $\mathrm{x}$ & - & - \\
\hline Frank and Kapila (2017) & - & - & $\mathrm{x}$ & - & - \\
\hline Furió et al. (2013a) & - & - & - & $\mathrm{X}$ & - \\
\hline Furió et al. (2013b) & $\mathrm{x}$ & - & - & - & - \\
\hline Furió et al. (2015) & $\mathrm{x}$ & - & - & - & - \\
\hline Giasiranis and Sofos (2016) & - & $\mathrm{X}$ & - & - & - \\
\hline Giasiranis and Sofos (2017) & - & $\mathrm{X}$ & - & - & - \\
\hline Guazzaroni (2013) & $\mathrm{x}$ & - & - & - & - \\
\hline Harley et al. (2016) & - & - & - & $\mathrm{X}$ & - \\
\hline Ho et al. (2017) & - & - & - & $\mathrm{X}$ & - \\
\hline Hsu (2017) & - & - & - & $\mathrm{X}$ & - \\
\hline Huang et al. (2016) & $\mathrm{X}$ & - & - & - & - \\
\hline Hung et al. (2017) & $\mathrm{X}$ & - & - & - & - \\
\hline Hwang et al. (2018) & - & - & - & $\mathrm{X}$ & - \\
\hline Joo-Nagata et al. (2017) & - & - & - & $\mathrm{X}$ & - \\
\hline Kamarainen et al. (2013) & $\mathrm{x}$ & - & - & - & - \\
\hline Kuo-Hung et al. (2016) & - & - & - & $\mathrm{X}$ & - \\
\hline Laine et al. (2016) & - & - & - & - & $\mathrm{X}$ \\
\hline Lee et al. (2016) & - & - & - & $\mathrm{X}$ & - \\
\hline Lin et al. (2013) & $\mathrm{x}$ & - & - & - & - \\
\hline Liou et al. (2017) & $\mathrm{x}$ & - & - & - & - \\
\hline Liou et al. (2016) & $\mathrm{x}$ & - & - & - & - \\
\hline Mahmoudi et al. (2017) & - & - & $\mathrm{x}$ & - & - \\
\hline Martín-Gutiérrez et al. (2015) & - & - & $\mathrm{X}$ & - & - \\
\hline Muñoz-Cristóbal et al. (2017) & $\mathrm{x}$ & - & - & - & - \\
\hline Muñoz-Cristóbal et al. (2018) & $\mathrm{x}$ & - & - & - & - \\
\hline Pérez-Sanagustín et al. (2014) & - & - & - & $\mathrm{x}$ & - \\
\hline Reyes et al. (2016) & - & - & $\mathrm{x}$ & - & - \\
\hline Reyes-Aviles and Aviles-Cruz (2018) & - & - & $\mathrm{x}$ & - & - \\
\hline Rodriguez-Gil et al. (2016) & - & - & $\mathrm{x}$ & - & - \\
\hline Schmitz et al. (2015) & $\mathrm{x}$ & - & - & - & - \\
\hline Schneider and Blikstein (2018) & $\mathrm{x}$ & - & - & - & - \\
\hline Sommerauer and Müller (2014) & - & - & - & - & $\mathrm{x}$ \\
\hline Wang (2017a) & - & - & - & $\mathrm{X}$ & - \\
\hline Wang (2017b) & - & $\mathrm{X}$ & - & - & - \\
\hline Wang et al. (2014) & $\mathrm{X}$ & - & - & - & - \\
\hline Yang and Liao (2014) & - & - & - & $\mathrm{X}$ & - \\
\hline Yilmaz (2016) & $\mathrm{X}$ & - & - & - & - \\
\hline Zhang et al. (2014) & $\mathrm{X}$ & - & - & - & - \\
\hline Zhang et al. (2016) & $\mathrm{X}$ & - & - & - & - \\
\hline Total & 27 & 3 & 9 & 16 & 2 \\
\hline
\end{tabular}

Note. "X” $\rightarrow$ Grounded; “-” $\rightarrow$ Not Provided. 
Maps (3 studies), DropBox (2 studies), Oracle (2 studies), Mediawiki (2 studies), 3D Studio Max (2 studies), OpenSceneGraph, YouTube, Youtopia, SketchUp, TapaCarp, Moon Finder, Sky Map, Apple Maps, Cloud Cities, Google Forms/Slides, Picasa, Moodle, CocoaAsyncSocket, and Weebly.

Regarding the operating systems used, Android (23 studies), iOS (19 studies), Windows (3 studies), and Symbian (1 study). Regarding the access platforms available to the students, it was verified that: Tablets (36 studies), Smartphones (30 studies), Head-Mounted Display (HMD) (4 studies), Computers (3 studies), Glasses ( 2 studies) and Phone (1 study) used these technologies to access the mobile augmented reality approaches. The results obtained demonstrate an expected trend, in which, Android and iOS operating systems were widely predominant, both being recognized in the academic and professional environment. In the same way, the use of this type of system is in agreement with the predominant types of devices, which were tablets and smartphones, compatible with this type of operating system, besides being commonly used in different purposes.

Analysing the selected articles, the theories/educational strategies used to promote students' mobile learning were also observed during access to the educational content contained in the mobile augmented reality application. In this perspective, the pedagogical approaches that were used are presented in Table 5. Nineteen studies did not specify the theory/educational approach used in their augmented reality applications.

We observed in the selected articles that several multimedia educational resources were presented in the mobile augmented reality approaches used for the purpose of promoting education, which were classified as: images (46 studies), videos (36 studies), texts (36 studies), 3D objects (30 studies), audios (12 studies), animations (7 studies), questions (7 studies), infographics (2 studies), maps (2 studies), chat (1 study), zoom-in/out (2 studies), 2D or 3D graphs (2 studies), web pages/links (2 studies), books, forum, whiteboard, hypertexts, mobile serious educational games, addresses, navigation, and compass. However, three articles did not specify the multimedia resource used.

Resources such as 3D objects, images, videos, and texts are considered essential points in the frequently developed approaches in the educational area, which conveys the reality identified in the analysed articles, in which, they had their predominance in relation to the other multimedia resources listed (Chang et al., 2014; Harley et al., 2016; Wang, 2017). In order to enable such a scale presentation of multimedia resources, the articles analysed used augmented reality strategies, which we verified as being Image-based (49 studies) and Location-based (23 studies). These results are related to the data presented previously, in which the predominant multimedia resources are related to the type of strategy of augmented reality more adopted, whose base is centered in Image.

Another aspect analysed in this research question is the methodologies used in SLR articles for the development of approaches with mobile augmented 
Table 5. Educational theories applied in MAR approaches.

\begin{tabular}{|c|c|c|c|c|c|c|c|c|c|c|c|c|c|c|c|c|c|c|c|c|}
\hline References & 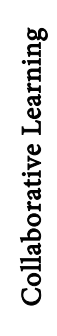 & 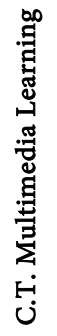 & 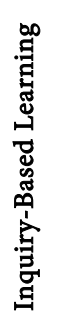 & 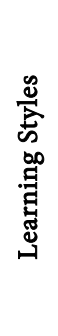 & 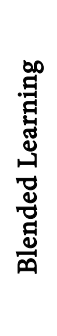 & 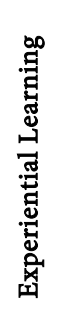 & 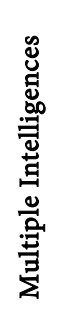 & 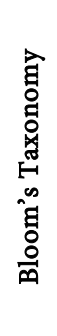 & 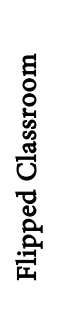 & 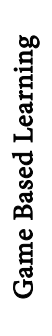 & 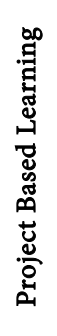 & 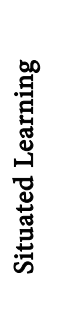 & 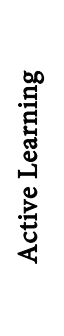 & 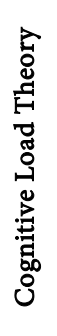 & 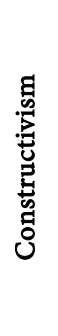 & 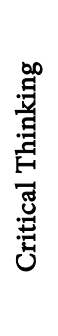 & 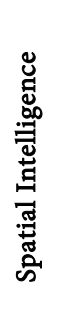 & 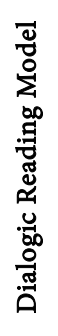 & 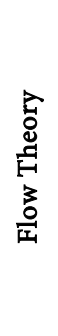 & 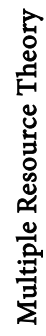 \\
\hline Akçayir et al. (2016) & - & $\mathrm{X}$ & - & - & - & - & - & - & - & - & - & - & - & - & - & - & - & - & - & - \\
\hline Botella et al. (2011) & - & - & - & - & - & - & - & - & - & $\mathrm{X}$ & - & - & - & - & - & - & - & - & - & - \\
\hline Bressler and Bodzin (2013) & - & - & $\mathrm{X}$ & - & - & - & - & - & - & - & - & - & - & - & - & - & - & - & - & - \\
\hline Bressler and Bodzin (2016) & $\mathrm{X}$ & - & - & - & - & - & - & - & - & - & - & - & - & - & - & - & - & - & - & - \\
\hline Chang and Hwang (2018) & - & - & - & - & - & - & - & - & $\mathrm{X}$ & - & $\mathrm{X}$ & - & - & - & - & - & - & - & - & - \\
\hline Chang et al. (2014) & - & - & - & - & - & - & - & - & - & - & - & - & - & - & - & - & - & - & - & - \\
\hline Chang et al. (2015) & - & - & - & - & - & - & - & - & - & - & - & - & - & - & - & - & - & - & - & - \\
\hline Chang et al. (2013) & - & - & $\mathrm{X}$ & - & - & - & - & - & - & - & - & - & - & - & - & - & - & - & - & - \\
\hline Cheng (2018) & - & - & - & - & - & - & - & - & - & - & - & - & - & - & - & - & - & - & - & - \\
\hline Cheng and Tsai (2014) & - & - & - & - & - & - & - & - & - & - & - & - & - & - & - & - & - & $\mathrm{X}$ & - & - \\
\hline Cheng and Tsai (2016) & - & - & - & - & - & - & - & - & - & - & - & - & - & - & - & - & - & - & - & - \\
\hline Chiang et al. (2014a) & - & $\mathrm{X}$ & $\mathrm{X}$ & - & - & - & - & - & - & - & - & - & - & - & - & - & - & - & - & - \\
\hline Chiang et al. (2014b) & - & $\mathrm{X}$ & $\mathrm{X}$ & - & - & - & - & - & - & - & - & - & - & - & - & - & - & - & - & - \\
\hline Cubillo et al. (2015) & - & - & - & - & - & - & - & - & - & - & - & - & - & - & - & - & - & - & - & - \\
\hline Delello (2014) & - & - & $\mathrm{X}$ & - & - & - & - & - & - & - & - & - & - & - & - & - & - & - & - & - \\
\hline Echeverría et al. (2012) & $\mathrm{X}$ & 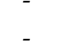 & $\begin{array}{l}\Lambda \\
-\end{array}$ & - & - & - & - & - & - & - & - & - & - & - & - & - & - & - & - & - \\
\hline Fonseca et al. (2014) & $\begin{array}{c}\Lambda \\
-\end{array}$ & - & - & - & - & - & - & - & - & - & - & - & - & - & - & - & - & - & - & - \\
\hline Fonseca et al. (2016) & - & - & - & - & - & - & - & - & - & - & $\mathrm{X}$ & - & - & - & - & - & - & - & - & - \\
\hline Frank and Kapila (2017) & - & - & - & - & - & - & - & - & - & - & - & - & - & - & - & - & - & - & - & - \\
\hline Furió et al. (2013a) & - & - & - & - & - & $\mathrm{X}$ & $\mathrm{X}$ & - & - & $\mathrm{X}$ & - & - & - & - & - & - & - & - & - & - \\
\hline Furió et al. (2013b) & - & - & - & - & - & $\mathrm{X}$ & $\mathrm{X}$ & - & - & - & - & - & - & - & - & - & - & - & - & - \\
\hline $\begin{array}{l}\text { Furió et al. (2015) } \\
\text { Giasiranis and Sofos (2016) }\end{array}$ & - & - & - & - & - & - & - & - & - & - & - & - & - & - & - & - & - & - & - & - \\
\hline $\begin{array}{l}\text { Glasiranis and Sofos (2016) } \\
\text { Giasiranis and Sofos (2017) }\end{array}$ & - & - & - & - & - & - & - & - & - & - & - & - & - & - & - & - & - & - & - & - \\
\hline Guazzaroni (2013) & - & - & - & - & - & - & - & - & - & - & - & - & - & - & - & - & - & - & $\mathrm{X}$ & - \\
\hline Harley et al. (2016) & - & - & - & - & - & - & $\mathrm{X}$ & - & - & - & - & $\mathrm{X}$ & - & - & - & - & - & - & - & - \\
\hline Ho et al. (2017) & - & $\mathrm{X}$ & - & - & - & - & - & - & - & - & - & - & - & - & - & - & - & - & - & - \\
\hline Hsu (2017) & - & - & - & $\mathrm{X}$ & - & - & - & - & - & - & - & - & - & - & - & - & - & - & - & - \\
\hline Huang et al. (2016) & - & - & - & $\mathrm{X}$ & - & - & - & - & - & - & - & - & - & - & - & - & - & - & - & - \\
\hline Hung et al. (2017) & - & - & - & - & - & $\mathrm{X}$ & - & - & - & - & - & - & - & - & - & - & - & - & - & - \\
\hline Hwang et al. (2018) & - & - & - & - & - & - & - & - & - & - & - & - & - & - & - & - & - & - & - & $\mathrm{X}$ \\
\hline Joo-Nagata et al. (2017) & - & - & - & - & - & - & - & - & - & - & - & - & $\mathrm{X}$ & - & - & - & - & - & - & - \\
\hline Kamarainen et al. (2013) & - & $\mathrm{X}$ & - & - & - & - & - & $\mathrm{X}$ & - & - & - & - & - & - & - & - & $\mathrm{X}$ & - & - & - \\
\hline Kuo-Hung et al. (2016) & - & - & - & - & - & - & - & - & - & - & - & $\mathrm{X}$ & - & - & - & - & - & - & - & - \\
\hline Laine et al. (2016) & - & - & - & - & - & - & - & - & - & - & - & - & - & - & - & - & - & - & - & - \\
\hline Lee et al. (2016) & - & - & - & - & - & - & - & - & - & - & - & - & - & - & - & - & - & - & - & - \\
\hline Lin et al. (2013) & $\mathrm{X}$ & - & - & - & $\mathrm{X}$ & - & - & - & - & - & - & - & - & - & - & $\mathrm{X}$ & - & - & - & - \\
\hline Liou et al. (2017) & $\mathrm{X}$ & - & - & - & - & - & - & - & - & - & - & - & - & - & - & - & - & - & - & - \\
\hline Liou et al. (2016) & - & - & $\mathrm{X}$ & - & - & - & - & - & - & - & - & - & - & $\mathrm{X}$ & - & - & - & - & - & - \\
\hline Mahmoudi et al. (2017) & - & - & - & - & - & - & - & - & $\mathrm{X}$ & - & - & - & - & - & - & - & - & - & - & - \\
\hline Martín-Gutiérrez et al. (2015) & - & - & - & $\mathrm{X}$ & - & - & - & $\mathrm{X}$ & - & - & - & - & - & - & - & - & - & - & - & - \\
\hline Muñoz-Cristóbal et al. (2017) & $\mathrm{X}$ & - & - & - & - & - & - & - & - & - & - & - & - & - & - & - & - & - & - & - \\
\hline Muñoz-Cristóbal et al. (2018) & $\mathrm{X}$ & - & - & - & - & - & - & - & - & - & - & - & - & - & - & - & - & - & - & - \\
\hline Pérez-Sanagustín et al. (2014) & - & - & - & - & - & - & - & - & - & - & - & - & - & - & - & - & - & - & - & - \\
\hline Reyes et al. (2016) & - & - & - & - & $\mathrm{X}$ & - & - & - & - & - & - & - & - & - & - & - & - & - & - & - \\
\hline Reyes-Aviles and Aviles-Cruz & - & - & - & - & - & - & - & - & - & - & - & - & - & - & - & - & - & - & - & - \\
\hline$(2018)$ & - & - & - & - & - & - & - & - & - & - & - & - & - & - & - & - & - & - & - & - \\
\hline Rodriguez-Gil et al. (2016) & - & - & - & - & - & - & - & - & - & - & - & - & - & - & - & - & - & - & - & - \\
\hline Schmitz et al. (2015) & - & - & - & - & - & - & - & - & - & - & - & - & - & - & - & - & - & - & - & - \\
\hline
\end{tabular}




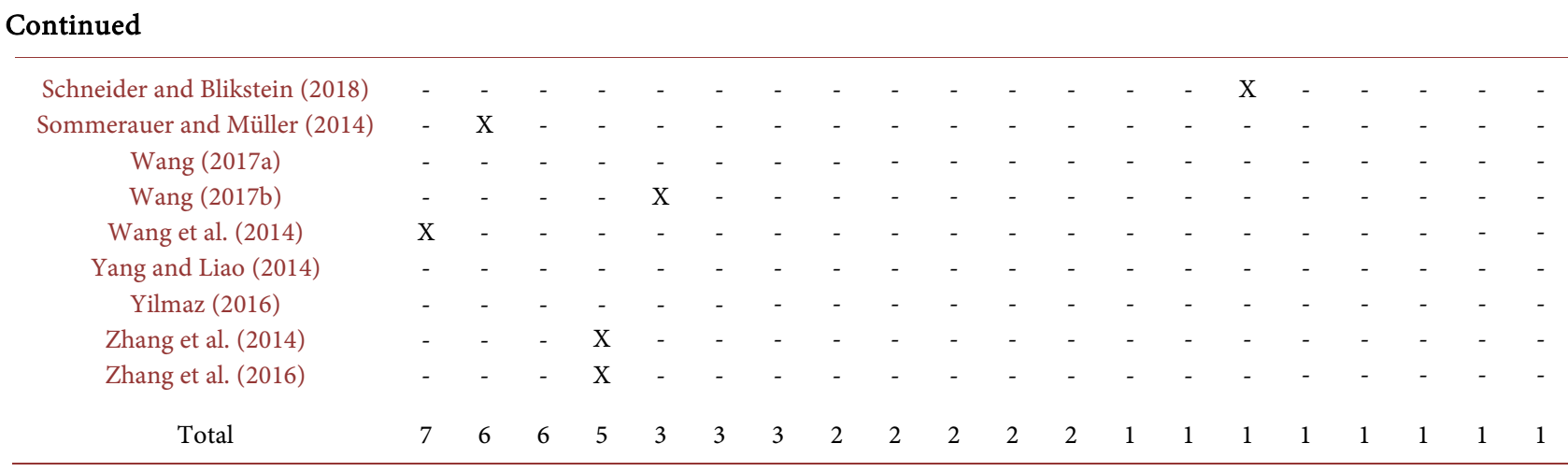

reality features. In this respect, we identified the following methodologies: $\mathrm{Hu}-$ man-Computer-Context Interaction (HCCI) (2 studies) (Chang et al., 2014; Chang et al., 2015), Android-based Science Spots AR (SSAR) (Laine et al., 2016), Emotional Mapping of Museum Augmented Places (EMMAP) (Guazzaroni, 2013), Eco-Discovery AR-based Learning Model (EDALM) (Huang et al., 2016), Design Principles for M-learning (Furió et al., 2013a), Systems Development Life Cycle (SDLC) (Furió et al., 2013a), 5E Instructional Model (Liou et al., 2017), and Historical Geo-Context-Embedded Visiting (HGCEV) (Chang et al., 2015). In addition to the procedures referenced above, it was also observed that other 50 articles did not specify the procedures adopted during the construction of the MAR approaches.

- RQ3: How the mobile augmented reality approaches used for educational purposes have been evaluated?

To answer this question, we analysed the selected articles in terms of evaluation factors, research design, educational level of the target audience, sample size, systematic approaches used to evaluate the augmented reality applications, data collection instruments and data analysis methods.

Regarding the evaluation factors, it was possible to identify that there are several factors that can be taken into account in this requirement (20 to the total). They have been used to assess the approaches to the mobile augmented reality applied in education (Table 6). Learning is usually the most evaluated factor (47 studies). Table 6 present the evaluation factors identified in the selected studies.

In terms of research design, we classified the selected investigations as illustrated in Section 2.2. We identified that most of the studies, 29 studies, were conducted in an ad-hoc format, that is, a more informal analysis, using comments from the participants and including details related to the observations made during the studies. Researches adopting the non-experimental research design (5 studies), typically, used questionnaires for data collection after the treatment. Others 23 researches adopted a formal research design. 14 studies adopted a formal experimental research design, where the students are randomized allocated in a control (continued to use the traditional system of the course) and an experimental group (using the MAR approach as treatment). In these studies, results were analysed from the tests performed (pre-test and post-test). Additional 9 
Table 6. Measured evaluation factors of articles.

\begin{tabular}{|c|c|c|c|c|c|c|c|c|c|c|c|c|c|c|c|c|c|c|c|c|}
\hline References & 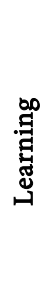 & 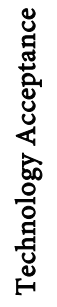 & 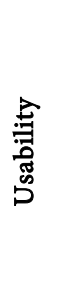 & 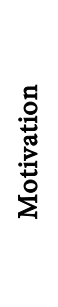 & 旁 & 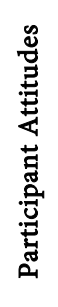 & 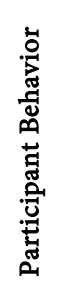 & 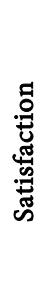 & 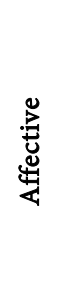 & 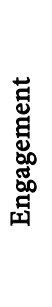 & 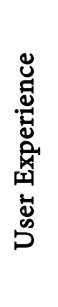 & 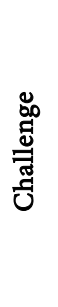 & 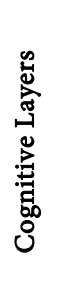 & 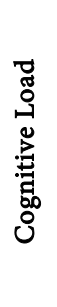 & 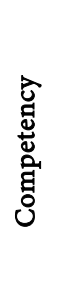 & 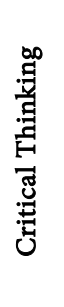 & 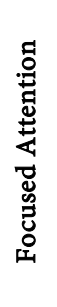 & 䍃 & 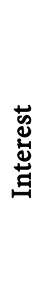 & 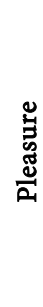 \\
\hline Akçayir et al. (2016) & $\mathrm{X}$ & - & - & - & - & $\mathrm{X}$ & - & - & - & - & - & - & - & - & - & - & - & - & - & - \\
\hline Botella et al. (2011) & - & $\mathrm{X}$ & - & - & - & - & - & - & - & - & - & - & - & - & - & - & - & - & - & - \\
\hline Bressler and Bodzin (2013) & $\mathrm{X}$ & - & - & - & - & - & - & - & - & - & - & - & - & - & - & - & - & - & - & - \\
\hline Bressler and Bodzin (2016) & $\mathrm{X}$ & - & - & - & $\mathrm{X}$ & - & - & - & - & $\mathrm{X}$ & - & - & - & - & - & - & - & - & - & - \\
\hline Chang and Hwang (2018) & $\mathrm{X}$ & - & - & $\mathrm{X}$ & - & - & - & $\mathrm{X}$ & - & - & - & - & - & - & - & - & - & - & - & - \\
\hline Chang et al. (2014) & $\mathrm{X}$ & - & - & - & $\mathrm{X}$ & $\mathrm{X}$ & $\mathrm{X}$ & - & - & - & - & - & - & - & - & - & $\mathrm{X}$ & - & - & $\mathrm{X}$ \\
\hline Chang et al. (2015) & $\mathrm{X}$ & - & - & - & - & $\mathrm{X}$ & - & - & - & - & - & - & - & - & - & - & - & - & - & - \\
\hline Chang et al. (2013) & $\mathrm{X}$ & - & - & - & - & - & - & - & - & - & - & - & - & - & - & - & - & - & - & - \\
\hline Cheng (2018) & - & $\mathrm{X}$ & - & - & - & - & - & - & - & - & $\mathrm{X}$ & - & - & - & - & - & - & - & - & - \\
\hline Cheng and Tsai (2014) & $\mathrm{X}$ & - & - & - & - & - & $\mathrm{X}$ & - & - & - & - & - & - & - & - & - & - & - & - & - \\
\hline Cheng and Tsai (2016) & $\mathrm{X}$ & $\mathrm{X}$ & - & - & - & - & - & - & - & - & - & - & - & - & - & - & - & - & - & - \\
\hline Chiang et al. (2014a) & $\mathrm{X}$ & - & - & - & - & - & - & - & - & - & - & - & - & - & - & - & - & - & - & - \\
\hline Chiang et al. (2014b) & $\mathrm{X}$ & - & - & $\mathrm{X}$ & - & - & - & - & $\mathrm{X}$ & - & - & - & - & - & - & - & - & - & - & - \\
\hline Cubillo et al. (2015) & - & - & $\mathrm{X}$ & - & - & - & - & - & - & - & - & - & - & - & - & - & - & - & - & - \\
\hline Delello (2014) & $\mathrm{X}$ & - & $\mathrm{X}$ & - & - & - & - & - & - & - & - & - & - & - & - & - & - & - & - & - \\
\hline Echeverría et al. (2012) & $\mathrm{X}$ & - & - & - & - & - & - & - & - & - & - & - & - & - & - & - & - & - & - & - \\
\hline Fonseca et al. (2014) & - & $\mathrm{X}$ & $\mathrm{X}$ & $\mathrm{X}$ & - & - & - & - & - & $\mathrm{X}$ & $\mathrm{X}$ & - & - & - & - & - & - & - & - & - \\
\hline Fonseca et al. (2016) & $\mathrm{X}$ & - & $\mathrm{X}$ & $\mathrm{X}$ & - & - & - & - & - & - & - & - & - & - & - & - & - & - & - & - \\
\hline Frank and Kapila (2017) & $\mathrm{X}$ & - & $\mathrm{X}$ & - & - & - & - & - & - & - & $\mathrm{X}$ & - & - & - & - & - & - & - & - & - \\
\hline Furió et al. (2013a) & $\mathrm{X}$ & $\mathrm{X}$ & - & - & - & - & - & $\mathrm{X}$ & - & - & - & - & - & - & - & - & - & $\mathrm{X}$ & - & - \\
\hline Furió et al. (2013b) & $\mathrm{X}$ & - & - & - & - & - & - & - & - & - & - & - & - & - & - & - & - & - & - & - \\
\hline Furió et al. (2015) & $\mathrm{X}$ & - & - & $\mathrm{X}$ & - & - & - & - & - & - & - & - & - & - & - & - & - & - & - & - \\
\hline Giasiranis and Sofos (2016) & $\mathrm{X}$ & - & - & - & $\mathrm{X}$ & - & - & - & - & - & - & - & - & - & - & - & - & - & - & - \\
\hline Giasiranis and Sofos (2017) & $\mathrm{X}$ & - & - & - & - & - & - & - & - & - & - & - & - & - & - & - & - & - & - & - \\
\hline Guazzaroni (2013) & $\mathrm{X}$ & - & - & $\mathrm{X}$ & - & - & - & $\mathrm{X}$ & - & - & - & - & - & - & - & - & - & - & - & - \\
\hline Harley et al. (2016) & $\mathrm{X}$ & - & - & - & - & - & $\mathrm{X}$ & - & - & - & - & - & - & - & - & - & - & - & - & $\mathrm{X}$ \\
\hline Ho et al. (2017) & $\mathrm{X}$ & - & - & - & - & - & - & - & - & - & - & - & - & - & - & - & - & - & - & - \\
\hline Hsu (2017) & $\mathrm{X}$ & - & - & - & $\mathrm{X}$ & - & - & - & - & - & - & - & - & $\mathrm{X}$ & - & - & - & - & - & - \\
\hline Huang et al. (2016) & $\mathrm{X}$ & - & - & $\mathrm{X}$ & - & $\mathrm{X}$ & - & - & $\mathrm{X}$ & $\mathrm{X}$ & - & $\mathrm{X}$ & - & - & $\mathrm{X}$ & - & - & - & $\mathrm{X}$ & - \\
\hline Hung et al. (2017) & $\mathrm{X}$ & - & - & $\mathrm{X}$ & - & - & - & - & - & - & - & - & - & - & - & - & - & - & - & - \\
\hline Hwang et al. (2018) & $\mathrm{X}$ & - & - & $\mathrm{X}$ & - & - & - & - & - & - & - & - & - & - & - & - & - & - & - & - \\
\hline Joo-Nagata et al. (2017) & $\mathrm{X}$ & - & - & - & - & - & - & $\mathrm{X}$ & - & - & - & - & - & - & - & - & - & - & - & - \\
\hline Kamarainen et al. (2013) & $\mathrm{X}$ & - & - & $\mathrm{X}$ & - & - & - & - & $\mathrm{X}$ & - & - & - & - & - & - & - & - & - & - & - \\
\hline Kuo-Hung et al. (2016) & $\mathrm{X}$ & - & - & - & - & - & - & - & - & - & - & - & - & - & - & - & - & - & - & - \\
\hline Laine et al. (2016) & $\mathrm{X}$ & - & $\mathrm{X}$ & $\mathrm{X}$ & - & - & - & - & - & - & - & - & - & - & - & - & - & - & - & - \\
\hline Lee et al. (2016) & $\mathrm{X}$ & - & - & - & - & - & - & - & - & - & - & - & - & - & - & $\mathrm{X}$ & - & - & - & - \\
\hline Lin et al. (2013) & $\mathrm{X}$ & - & - & - & - & - & - & - & - & - & - & - & - & - & - & - & - & - & - & - \\
\hline Liou et al. (2017) & $\mathrm{X}$ & $\mathrm{X}$ & - & - & - & - & - & - & - & - & - & - & - & - & - & - & - & - & - & - \\
\hline Liou et al. (2016) & $\mathrm{X}$ & - & - & - & - & - & - & - & - & - & - & - & - & - & - & - & - & - & - & - \\
\hline Mahmoudi et al. (2017) & $\mathrm{X}$ & - & - & - & - & - & - & - & - & - & - & - & $\mathrm{X}$ & - & - & - & - & - & - & - \\
\hline Martín-Gutiérrez et al. (2015) & - & $\mathrm{X}$ & $\mathrm{X}$ & - & - & - & - & $\mathrm{X}$ & - & - & - & - & - & - & - & - & - & - & - & - \\
\hline Muñoz-Cristóbal et al. (2017) & $\mathrm{X}$ & - & - & - & - & - & - & - & - & - & - & - & - & - & - & - & - & - & - & - \\
\hline Muñoz-Cristóbal et al. (2018) & - & $\mathrm{X}$ & - & - & - & - & - & - & - & - & - & - & - & - & - & - & - & - & - & - \\
\hline Pérez-Sanagustín et al. (2014) & $\mathrm{X}$ & - & - & - & - & - & - & - & - & - & - & - & - & - & - & - & - & - & - & - \\
\hline Reyes et al. (2016) & - & $\mathrm{X}$ & $\mathrm{X}$ & - & - & - & - & - & - & - & $\mathrm{X}$ & - & - & - & - & - & - & - & - & - \\
\hline Reyes-Aviles and Aviles-Cruz (2018) & - & $\mathrm{X}$ & - & - & - & - & - & - & - & - & - & - & - & - & - & - & - & - & - & - \\
\hline Rodriguez-Gil et al. (2016) & - & $\mathrm{X}$ & - & - & - & - & - & - & - & - & - & - & - & - & - & - & - & - & - & - \\
\hline Schmitz et al. (2015) & $\mathrm{X}$ & - & $\mathrm{X}$ & - & - & - & - & - & - & - & - & - & - & - & - & - & - & - & - & - \\
\hline Schneider and Blikstein (2018) & $\mathrm{X}$ & $\mathrm{X}$ & - & - & - & - & - & - & - & $\mathrm{X}$ & - & - & - & - & - & - & - & - & - & - \\
\hline
\end{tabular}




\section{Continued}

$\begin{array}{cccccccccccccccccccccc}\text { Sommerauer and Müller (2014) } & \mathrm{X} & - & - & - & - & - & - & - & - & - & - & - & - & - & - & - & - & - & - & - \\ \text { Wang (2017a) } & \mathrm{X} & - & - & - & - & - & - & - & - & - & - & - & - & - & - & - & - & - & - & - \\ \text { Wang (2017b) } & \mathrm{X} & - & \mathrm{X} & - & - & - & - & - & - & - & - & - & - & - & - & - & - & - & - & - \\ \text { Wang et al. (2014) } & \mathrm{X} & - & - & - & - & - & - & - & - & - & - & - & - & - & - & - & - & - & - & - \\ \text { Yang and Liao (2014) } & \mathrm{X} & - & \mathrm{X} & - & - & - & \mathrm{X} & - & - & - & - & - & - & - & - & - & - & - & - & - \\ \quad \text { Yilmaz (2016) } & - & \mathrm{X} & \mathrm{X} & - & - & \mathrm{X} & \mathrm{X} & - & - & - & - & - & - & - & - & - & - & - & - & - \\ \text { Zhang et al. (2014) } & \mathrm{X} & - & - & - & \mathrm{X} & - & - & - & \mathrm{X} & - & - & - & - & - & - & - & - & - & - & - \\ \text { Zhang et al. (2016) } & \mathrm{X} & - & - & - & - & - & - & - & - & - & - & - & - & - & - & - & - & - & - & - \\ \text { Total } & 47 & 13 & 12 & 11 & 5 & 5 & 5 & 5 & 4 & 4 & 4 & 1 & 1 & 1 & 1 & 1 & 1 & 1 & 1 & 2\end{array}$

studies adopted a quasi-experimental research design, using experimental and control groups, but without a randomized allocation.

As for the educational level of the target audience of the selected investigations, we identified that the most of the mobile augmented reality approaches (26 studies) were applied in the undergraduate level, typically with the objective of to teach a specific content in an engaged and immersive way for the students. On the other hand, the mobile augmented reality educational approaches also have been applied to other target audience, such as high school students (11 studies), elementary school students (16 studies), graduate students, teachers, and two studies do not specify their target audience.

In relation to sample size, the majority of the evaluations ( $53 \%$ of the selected studies) were conducted with a small sample size (1 to 60 participants). This number typically corresponds to the number of students enrolled in one class in which the study is conducted. On the other hand, 14 evaluations ran with more than 100 participants. Regarding the other studies, 10 researches had a range of participants from 61 to 80 people, whereas only 3 studies had a group between 81 and 100 participants, which can be considered as a common situation in this educational environment. The trend of participants is concentrated in the range of 1 - 60 participants, since a number greater than this is usually complex to be managed for teachers.

In terms of evaluation of the studies, 95\% (54 studies), did not use any well-defined and systematic evaluation approach. This result is consistent with the previous one, indicating that most of the studies are evaluated in an ad-hoc way, not clearly defining an evaluation objective and research design. In this respect, we identified as a research gap the lack of a well-defined evaluation approach in order to provide a comprehensive support in the systematic evaluation of MAR approaches.

On the other hand, one study used the ISO 9241-11 (1998) international standard (Fonseca et al., 2014) in order to analyse the usability of the augmented reality technology. Other two studies evaluate MAR approaches with Evaluand-oriented Responsive Evaluation Model (EREM) (Muñoz-Cristóbal et al., 2017) and (Muñoz-Cristóbal et al., 2018). The EREM is a framework developed to guide practitioners involved in the evaluation of a huge variety of innovations in collaborative ubiquitous learning environments (Muñoz-Cristóbal et al., 
2017).

In terms of data collection instruments used in the evaluations, we identified that the most of the studies collect data using a questionnaire (53 studies). The questionnaires are usually used in a more informal approach, that is, ad-hoc. This means that there is no formal definition of models and techniques for constructing the questionnaires, these are developed in a more empirical way. In 21 studies, an interview was conducted after the treatment in order to capture the students' opinions, and 6 studies also used the recording of verbal communications.

Two studies use recognized questionnaires as data collection instruments, such as the System Usability Scale (SUS) (Brooke, 1996) (3 studies) and Technology Acceptance Model (TAM) (Davis, 1989) (3 studies).

Different types of data collection methods also are used to evaluate, typically, a specific evaluation factor by one study, such as Flow Experience (5 studies) (Chang et al., 2014; Zhang et al., 2014; Giasiranis \& Sofos, 2016; Hsu, 2017; Giasiranis \& Sofos, 2017). Among the studies that evaluated Flow Experience, two studies reported the use of Flow State Scale (FSS) (Giasiranis \& Sofos, 2016; Giasiranis \& Sofos, 2017), Teacher Communication Behavior Questionnaire (TCBQ) (Yang \& Liao, 2014), Collaborative Inquiry Learning Behavior (Wang et al., 2014), Index of Learning Styles (ILS) (Hsu, 2017; Mahmoudi et al., 2017) (2 studies) and VAK Learning Styles Self-Assessment Questionnaire (Zhang et al., 2016), Conceptual Survey of Electricity (CSE) (Echeverría et al., 2012), Bipolar Laddering Assessment (Fonseca et al., 2016), 5-Stage Learning Strategy (Chiang et al., 2014b), Interaction Analysis Model (IAM) (Chiang et al., 2014b), Sense of place (SOP) (Chang et al., 2015), Behavioral avoidance test (BAT) (Botella et al., 2011), Fear of spiders questionnaire (FSQ) (Botella et al., 2011), Spider phobia beliefs questionnaire (SPBQ) (Botella et al., 2011), Anxiety Disorders Interview Schedule (ADIS-IV) (Botella et al., 2011), Human-guidance-only model (Huang et al., 2016), Eco-discovery AR-based learning model (EDALM) (Huang et al., 2016), Emotion self-assessment questionnaire (Huang et al., 2016), Experiential activity questionnaire (Huang et al., 2016), Quantitative Content Analysis (QCA) (Lin et al., 2013), Cognitive Load Questionnaire (Hsu, 2017), Foreign Language Classroom Anxiety Scale (FLCAS) (Hsu, 2017), System Usability Questionnaire (Frank and Kapila, 2017), ISO 9241-11 (Fonseca et al., 2014), and Embedded Figures Test (EFT) (Ho et al., 2017).

Additional data collection methods also are used (one method for each study) including the analysis of the students' profile (3 studies) (Fonseca et al., 2014; Akçayir et al., 2016; Fonseca et al., 2016), attitude (Akçayir et al., 2016), and behavior (Chang et al., 2014), student self-report and eye tracking (Harley et al., 2016).

The identification of the data analysis methods was performed in order to interpret the data collected in the evaluations, the most of the selected studies used quantitative data analysis, ranging from inferential to descriptive statistics. 35 
studies used both quantitative and qualitative data analysis methods and 22 studies used only qualitative analysis, typically analysing comments and students' perceptions through content analysis (4 studies), narrative analysis (3 studies), and discourse analysis.

Regarding the descriptive statistics, the mean is typically used by 47 studies, in order to carry out a measurement of trends that are centralized. Additional descriptive methods include median ( 3 studies) and weighted value, besides several studies also use as a complementary measurement the analysis the dispersion with the application of level of variation, involving 42 studies with standard deviation, 5 studies with relative frequency, 4 studies with range and 2 studies with variance. We also applied types of measures that allowed to examine the dependency between variables, including Pearson (5 studies) and Spearman (2 studies) correlation coefficient, Scheffé (2 studies), Least Squares Difference (LSD) (2 studies), Multiple Regression Analysis (2 studies), and Linear Regression. It is important to highlight that one of the possible alternatives to be used with the central trend measures is the application of graphs for data visualization, among which it was possible to identify 14 studies using frequency diagrams, 10 studies using line charts, 4 studies using boxplots and 1 study using a pie chart.

With respect to inferential statistics, techniques were used that involved the application of hypothesis tests in order to carry out the analysis of a specific question. In this respect, we identified that 21 studies used the t-test (commonly used in parametric tests that compare 2 samples with a factor). Four studies used Mann-Whitney, a nonparametric alternative to the t-test. 4 studies used the Wilcoxon method, which can be used in paired tests, similar to the t-test application. Others inferential statistics methods include Cohen's kappa (19 studies), Chi-2 (6 studies), Levene's test (3 studies), Shapiro-Wilk (3 studies), Inter-rater reliability (2 studies), Fisher (2 studies), Lag Sequential Analysis (2 studies), Kolmogorov-Smirnov (2 studies), Coefficient of Variation, Cramer, Sequential Analysis, McNemar, Tukey's range test, and K-Mean.

With regard to the researches that were centralized in the analysis with 2 forms of treatment and 1 factor, we identified that 17 studies used ANOVA, whereas 10 studies used ANCOVA, 4 studies used Kruskal-Wallis, 2 studies used MANCOVA and 1 study used Dunn. In addition, 16 studies also used Cronbach's Alpha coefficient in order to evaluate the reliability of the instruments used in the data collection process.

\section{Discussion}

Analysing the literature over the past few years (2011-2018), we identified a considerable number of investigations (57 studies) applying the mobile augmented reality approaches with educational purposes in the different context and educational levels. In this respect, based on our results, we identified an increase in the number of the articles published over the past few years, this result seems to be indicating that this research area is attracting more interesting due to the poten- 
tial of contributions to the students' learning and engagement (Dunleavy \& Dede, 2014; Chiang et al., 2014b; Lee et al., 2016).

With respect to the knowledge areas that the mobile augmented reality approaches are applied (RQ1), STEAM is presented as a teaching approach in which traditional disciplines in the areas of Science, Technology, Engineering, Arts and Mathematics are structured into an integrated curriculum proposal, focusing on problem-solving and skills development, critical thinking and from creativity to decision-making and future challenges (Lorenzin, Assumpção, \& Rabello, 2016).

We can observe that most of the studies (26) are applied in Science. The area of Science is traditionally characterized by the use of real laboratories, which help students in the construction of experiments and in the visualization of phenomena presented to them theoretically in the classroom. Chiu et al. (2015) explain that physical laboratories also give the students opportunities to interact directly with the scientific phenomena being studied. On the other hand, it is necessary to take into account that physical laboratories may not contain all apparatus necessary to present a rich experience in details, especially those at micro molecular level, which can result in difficulties of understanding by the student. In this context, MAR approaches have been applied in the educational scope, seeking to represent physical and chemical phenomena in micro and macromolecular scale, through simulated 3D virtual representations. However, we also identified a trend in the use of MAR approaches in the areas of Technology ( 3 articles), Engineering ( 9 articles), Art (12 articles), Mathematics ( 2 articles), and other areas ( 5 articles). This increase in the adopting of MAR approaches in different knowledge areas, indicate that is important to identify uniform patterns in terms of educational and technological requirements to be considered in the development in order to contribute to their continuous improvement.

Analysing the development of mobile augmented reality approaches for educational purposes (RQ2), we can observe that regarding the development platforms, the most used platforms were Layar (5 studies), Unity 3D (5 studies) and XCode (5 studies). These platforms are considered consolidated and robust tools for MAR approaches development, also confirming the results of (Nguyen \& Dang, 2017; Frank \& Kapila, 2017). However, it is important to note that over the years there has been a growing use of augmented reality editing platforms, such as Metaio (recently renamed ARKit), Vuforia, and Aurasma (recently renamed HP Reveal). This growing demand for augmented reality editing frameworks, according to Herpich, Guarese and Tarouco (2017), is related to the eventual difficulty faced by professionals that lack the experience in the area of computational solutions while trying to develop software for educational purposes, such as educators and researchers of any area remote to computing. However, another alternative is the augmented reality developing tools that offer an AR editing platform may ease or even make possible the high-level development process of educational softwares, e.g., it might facilitate the operation of 
creating software without requiring the knowledge needed to implement algorithms. This becomes true once that these platforms do not require the creator to write any code for the algorithms, demanding only that he adds AR resources, such as virtual media and three-dimensional models, to a web-based management platform (Herpich, Guarese, \& Tarouco, 2017).

Regarding the operating systems used to run the mobile augmented reality approaches, we identified Android (23) and iOS (19), both operating systems most popular in the mobile market currently. This factor highlights the importance of choosing a mobile augmented reality development platform that supports the most commonly used operating systems. However, an alternative to eventual incompatibilities of the user's mobile device operating system with the MAR application is to use platforms that offer proprietary applications such as Augment, Aurasma, BlippAR, CraftAR, LayAR, PixLive, and Wikitude, which in addition to offering an AR editing platform for the user to create augmented reality contents, also make the application available for different operating systems, requiring only the user to install on their smartphone or tablet.

Although a significant number of articles do not mention the pedagogical approach used or explain the reason for non-use, in general, the studies use a combination of educational strategies and ad-hoc definitions (18 studies), it was possible to verify that there is a tendency among articles analysed in using the educational theories:

Collaborative Learning (7 studies): Mobile augmented reality have frequently been used to support collaborative learning because allow the sharing of ideas, interactions, discussions, brainstorming, and collaboration with other classmates (Lee et al., 2016); Cognitive Theory of Multimedia Learning (6 studies), which related to this theory, Sommerauer and Müller (2014) argues that augmented reality inherently implements a subset of the design principles formulated in the CTML, namely, the multimedia principle, the spatial contiguity principle, the temporal contiguity principle, the modality principle, and the signaling principle; and Inquiry-Based Learning (6 studies): MAR-based inquiry learning activity is able to engage the students in more interactions for knowledge construction, because is a pedagogical method based on the investigation of questions, scenarios or problems (Chiang et al., 2014b).

In summary, although most of the studies do not use a pedagogical approach, it is essential considered it in the design of the MAR approach, due to the fact that is the pedagogical approach that determines the learning process and directly influencing in the students' learning (Wang et al., 2017).

In terms of how the pedagogical contents are being presented to students and how the students interact with these educational resources, we have identified that the most used multimedia resources were images (46 studies), videos (36 studies), texts (36 studies), 3D objects (30 studies), audios (12 studies) and animations ( 7 studies). These multimedia resources were the most used because they allow the visualization of educational contents and also the materialization 
of abstract concepts to the students (Huang et al., 2016; Yoon et al., 2017). This result confirms the arguments of Specht et al. (2011) and Santos et al. (2014a), indicating that the educational potential of augmented reality consists in the presentation of multimedia resources to the students, motivating the interaction and stimulate learners to learn abstract ideas using different resources.

Regarding the interaction mode of students with the multimedia resources in augmented scale, we identified that the traditional method was the most used, through the use of markers of augmented reality (Image-based, 49 studies), a result that was expected by us, due to the fact that it is the tracking used since the appearance of augmented reality until today, also confirming the results presented by Chang, Wu and Hsu (2013) and Ibanez et al. (2016). Another prominent feature in mobile augmented reality approaches found in SLR articles is Location-based (23 studies). Harley et al. (2016) argue that the location-based learning scenarios emphasize the affordances of mobile devices and mobile augmented reality to deliver information about the physical environment learners are exploring, allowing them to collect evidence, or investigate issues.

In order to verify how mobile augmented reality approaches are being developed for educational purposes, we analysed the development methodologies used and identified that only seven procedures were presented for the construction of mobile augmented reality education solutions. Although the SLR demonstrates a high number of articles that do not present the development methodology used in the construction of MAR approaches (50 studies), it is important to note that, through the verification of the methods found, it was possible to verify that most use principles of instructional design and techniques for the development of mobile learning, considering the use of multimedia resources and resources inherent to mobile devices, but without specifically considering the mobile augmented reality features, which can be seen in the respective methods: Human-Computer-Context Interaction (HCCI) (2 studies) (Chang et al., 2014; Chang et al., 2015); Design Principles for M-learning (Furió et al., 2013a); Systems Development Life Cycle (SDLC) (Furió et al., 2013a); and Historical Geo-Context-Embedded Visiting (HGCEV) (Chang et al., 2015). However, the methodologies built to assist in the development of mobile augmented reality approaches found in the SLR were: 1) Android-based Science Spots AR (SSAR) - where the authors define the concept and architecture of the SSAR platform that enables the construction of story-driven learning games for science education using AR and context-awareness (Laine et al., 2016); 2) Eco-Discovery AR-based Learning Model (EDALM) -EDALM integrates AR technology with the four stages of Kolb's experiential learning cycle: concrete experience, reflective observation, abstract conceptualization, and the active experimentation (Huang et al., 2016); 3) Emotional Mapping of Museum Augmented Places (EMMAP) - is a format aimed to develop innovative pedagogies, using handheld technology combined with QR codes, broadcasting and augmented reality (Guazzaroni, 2013); and the 5E Instructional Model-which integrates guided 
activities to the teaching of science including five stages: engagement, exploration, explanation, elaboration, and evaluation (Liou et al., 2017).

Analysing the evaluations of the selected mobile augmented reality approaches (RQ3), in terms of evaluation factors, the learning was the most evaluated factor (47 studies). It was possible to identify that one of the main issues listed and addressed in the analysed studies is the learning gain resulting from approaches of MAR. These can also be integrated in the Evaluation factor, essential in the measurement of learning, a wide variety of factors are considered, not allowing the identification of any clear pattern in the evaluation factors.

The most of the articles analysed used this factor to evaluate the experience of using the mobile augmented reality application, since the evaluation of the impact on participants' teaching and learning processes when using this approach is important in order to identify the contributions and, mainly, the opportunities for improvement that these approaches can enhance in students' learning. MAR is being applied in various educational domains, it can help learners to gain a deeper understanding, experience embedded learning content in real world overlays, or explore content driven by their current situation or environmental context (Specht et al., 2011).

In addition to learning, other factors are also considered in the evaluations, such as the usability evaluation (12 studies), in which the objective is to evaluate users' experience of using the application, seeking to implement improvements in the adopted approach. This process is intrinsically linked to the issue of user motivation (11 studies) and acceptance of the use of this type of technology (13 studies), these factors are considered in the evaluations, due to the fact that a positive user experience, a possible increase in motivation in continuing to use the mobile augmented reality application in their education. The lack of motivation can be a major obstacle that prevents learner success (Jeamu et al., 2008; Di-Serio, Ibáñez, \& Koos, 2013). Thus, learning strategies that connect with students' interests and provide them with opportunities to take an active part in their instruction can lead to increased engagement, effort, and eventual success (Theall, 1999; Di-Serio et al., 2013).

From the identification of the results, it was possible to notice that a great part of the researches was carried out without a scientific rigor, which can be classified as ad-hoc study, totaling 29 articles. With respect to experimental and quasi-experimental research, 14 and 9 articles were found, which may be motivated by the complexity and effort involved in experimental processes, with the use of experimental and control groups, and a detailed analysis of the data and in-depth discussion. It is important to emphasize that in this type of experiment, the size of the sample should be significant, that is, with a large number of participants, so that grouping can be performed (All et al., 2016). It was also possible to identify that the non-experimental approach was used in five studies, in which a final test was commonly adopted to measure student learning after using the MAR approach. 
Regarding the data collection instruments, the most of the selected studies (53 articles) used a questionnaire. Typically, these questionnaires are developed in an informal and ad-hoc manner or with open-ended questions, without defining a measurement model in order to derive questionnaire items based on theoretical constructs. Thus, these studies can be questionable with respect to the validity of the results obtained. An alternative for this strategy may be the attempt to create questionnaires based on existing standards, which could increase the validity of data collection and analysis.

In this context, the target public becomes an important aspect to be observed, in which the majority of studies were centralized in the use of undergraduate students (26 articles), being a common public to be used in academic research, which are participants who are studying specific topics in an area of knowledge, which are generally addressed as objects of study in articles. It is important to highlight in the data collected from this requirement, the low number of researches involving graduate students and pre-service teachers, which may be considered unexpected, since it is an active target audience in the academic environment.

Another important point that is interconnected to the target audience is the number of participants in each survey analysed. The expected trend, which was verified consists of a small sample size of the participants in the validations of the articles, which was centered in up to 60 participants $(53 \%$ of the selected articles), which study types that were mostly adopted, which were ad-hoc and non-experimental, with predominance of the use of questionnaires and descriptive analyses. The articles that had a greater number in the sample of participants ( $47 \%$ of the selected articles) referred to the use of experimental researches with the application of statistical techniques, with the objective of evaluating the impact on the teaching and learning processes of the use of mobile applications of augmented reality.

Another factor analysed was the high number of studies that did not adopt or strictly follow a specific model, method or framework for the evaluation of augmented reality in mobile devices during the conduction of the surveys (95\% of the selected articles), which may be considered an important factor to be highlighted. The high number of works without using a specific method opens new research possibilities to be explored in this scope, with the development of new methods, methodologies and frameworks for the systematic evaluation of mobile augmented reality approaches.

Besides, it must be considered that there are currently not several alternatives to be explored for specific models, methods or frameworks for the evaluation of the initiatives in the scope of MAR, being that the existing methods or have been adapted from other areas or need to be better explored in the context of mobile learning. This factor is related with the high number of researches conducted in the ad-hoc manner, which does not have a high scientific rigor, which is another essential factor for which methods of this size have not been applied in greater 
quantity.

The RQ3 also addresses the data analysis methods used in the evaluations. Most of the studies (35) used both quantitative and qualitative data analysis methods, and 22 studies used only qualitative analysis. The adoption of this type of statistical technique assists in the identification of the students' learning level, the existing differences and observations to be made (Navarro \& van der Hoek, 2009; Hainey et al., 2016).

Qualitative analysis is predominantly used due to the fact that researches involving the evaluation of students' learning and the impact of the use of augmented reality resources in mobile devices needs the use of analytical techniques to assess whether there were significant differences in participant learning. The use of a complementary form of qualitative analysis is observed as an important indicator to support the results obtained quantitatively, since the interpretation of the results through questionnaires of opinion, interviews, and observations becomes essential to infer the impact and differential caused in the learning of the individual when using resources linked to the augmented reality in mobile devices.

\section{Threats to Validity}

It is important to highlight that in any SLR there are threats of validity to the presented results. In this way, during the execution of the SLR protocol, we seek to identify the potential threats and possible strategies to be applied to minimize the eventual effects on our research.

Publication Bias: Systematic reviews suffer from the common bias that positive outcomes are more likely to be published than negative ones (Kitchenham et al., 2010). However, this question was not considered a threat to our research, because instead of focusing on the impact on mobile augmented reality approaches, we aim at eliciting how these approaches have been applied in education.

Identification of Studies: One of the major problems with SLRs is finding all the relevant studies (Kitchenham et al., 2010). In this case, we performed manual searches on each of the thirteen sources in order to avoid eventual losses. In addition, we constructed a sequence of the research (Figure 1) to be as inclusive as possible, considering not only fundamental concepts but also the different terminologies (Table 1).

Study selection and data extraction. Threats related to study selection were attenuated with a detailed definition of the inclusion and exclusion criteria, accompanied by a rigid protocol for the study selection, used by all authors in a systematic way. To mitigate possible threats in the data extraction stage, we define for each research question a high level of detail, with different data items to be extracted. In addition, we defined and documented a rigid protocol for the study selection and all authors conducted the selection together always discussing the selection until consensus was achieved. Another issue is that no in- 
ter-rater reliability was conducted. In this respect, taking into consideration that the review has been done by four researchers (the authors) in constant cooperation throughout the analysis, such statistical analysis of the consistency would not provide significant results.

Limitations. Even though a rigid protocol was created and used to conduct this SLR and a joint process between authors, in some cases it becomes necessary to use a more evidence-based methodology to describe and improve the reporting of the systematic review, as an example to identify the risk of bias in individual studies. One of the major problems with SLRs is finding all the relevant studies because it is possible that the search string misses some studies that used different terminology to describe their study (Kitchenham et al., 2010).

Another limitation consists in the supply of data, once the authors selected only thirteen major journals on the subject under investigation in the SLR. Another limitation observed was only the analysis of the scientific literature, since the protocol did not contemplate processes for the collection, extraction, and analysis of gray literature, for example through a Multivocal Literature Review (Calderón et al., 2018). Due to the large number of databases analysed and because they were extracted from specific journals of the research area in question, it was not considered necessary to expand the research with other types of approaches, such as the research of the references of each analysed article or the inclusion of theses and dissertations for the scope of this work. Although this did not significantly affect this research, as previously explained, this factor can be considered a limitation identified for the scope of this work.

\section{Conclusion}

In this article, we present the state-of-the-art on how the mobile augmented reality has been used for educational purposes, considering the studies published between 2011 and 2018. We identified 57 articles applying the mobile augmented reality in different knowledge areas and we analysed them in terms of how these approaches have been developed and evaluated.

The 57 articles were categorized according to STEAM approach, which demonstrate the interdisciplinary character that MAR approaches can be applied. In that scope, the themes are explored in an investigative way through inter and transdisciplinary proposals, starting from the proposition of a problem, which can be expanded to the realization of projects, exploring concepts and materials in the application of knowledge and can be based on active learning (Lorenzin et al., 2016). This fact highlights the positive potential for the development of different MAR approaches in a variety of teaching environments.

We observed that between the years 2013 and 2017 the publications demonstrated a significant advance in the use of educational strategies in the application of the mobile augmented reality in the education. Typically, the analysed studies used at least one educational strategy or theory, among which we can emphasize the Collaborative Learning (Dillenbourg, 1999), Multimedia Learning 
(Mayer, 1997) and Inquiry-based Learning (Bruner, 1961). Another relevant aspect observed in the analysis of the articles is the multimedia educational resources presented in mobile augmented reality approaches, in which educational resources involving the use of images, videos, audios, 3D objects, and animations were highlighted, confirming also the results of Santos et al. (2014b). We identified that mobile augmented reality has shown an exponential growth with favorable signs to contribute to education, confirming also the results presented for the development of these technologies in the most recent New Media Consortium Horizon Report (Becker et al., 2017).

Regarding the development of the mobile augmented reality approaches, although there is a trend to develop approaches for executing on Android and iOS operating systems, there is not a consensus in terms of platforms (SDKs, Frameworks, and Plugins), typically these technical requirements are defined based on the expertise of the development team, confirming also the results of Herpich, Guarese and Tarouco (2017) and not defined based on empirical evidence of the effectivity of these platforms. Consistent with the lack of consensus in the platforms is the lack of the use of a developing methodology. Typically the studies are developed in an unsystematic manner, only considering aspects of human-computer interaction and instructional design.

The encountered studies also vary largely in terms of the aspects used in the evaluations. In terms of evaluation factors, besides evaluating the learning effect, the studies also consider usability, motivation, technology acceptance, etc., which results in no standard in analysing the student. In addition, most evaluations were conducted in a more flexible form (ad-hoc) for the research, measurement, and data collection, and analysis, not using a systematic method specifically developed for the evaluations of this kind of approach, and thus, evidencing the lack of the scientific rigor applied in the evaluations.

Some results presented in this research are related to discussions carried out in previous research, such as the studies of Dünser et al. (2008) and Dey et al. (2018). Dünser et al. (2008) evidenced an advance in the evaluation of approaches in augmented reality, being this point also emphasized by Dey et al. (2018), in which the authors identified the predominant use of questionnaires in evaluations. This result was observed in this research too, but we have identified that the MAR approaches assessment has used other data collection tools, such as assessment notes and observations supplemented by the use of interviews and system logs.

Dey et al. (2018) identified that there has been a growth of research in the educational field and few approaches that emphasize collaborative tasks. We identified that educational MAR approaches continue to expand, especially in areas covered by STEAM, which are exacerbated by the increasing use, accessibility and pervasiveness of mobile devices. In addition, we also identify that there is a shortage of more consistent and uniform patterns in terms of methods for systematically developing and evaluating MAR approaches. 
The focus of this research was centered on the educational field with emphasis on the use of mobile devices, which allowed the identification of some particularities: MAR approaches in the educational area has a greater focus on student learning evaluation (use of focused data collection instruments and statistical analysis methods); the increasing use of frameworks and SDKs, which support the development of prototypes in this scope; the construction of prototypes by people without deep technological knowledge is a proven trend, in which applications such as Aurasma (HP Reveal), Layar, Wikitude (and others) have facilitated the creation of new educational alternatives; the creation of models for evaluating students learning tends to grow in future.

In summary, with respect to the educational multimedia resources in RA available for interaction, the analysis of the data allowed to verify that few MAR approaches are following the constant evolutions of the technology and of the new demands from users. In fact, 60 to 80 percent of studies use obsolete resources such as images and texts. This demonstrates the need to develop new educational resources that accompany well-known indicators of new technologies in education and multimedia resources, such as the New Media Consortium Horizon Report (Becker et al., 2017). In contrast, we also identified that exists a need for identification of more consistent and uniform patterns in terms of methods for systematically develop and evaluate mobile augmented reality approaches with the objective of getting data to apply a basis for a decision on the application of such approaches and/or their continuous improvement for the educational purposes.

\section{Acknowledgements}

This research is supported by CAPES (Coordination for the Improvement of Higher Education Personnel) and CNPq (National Council for Scientific and Technological Development), Brazilian government entities focused on scientific development.

\section{Conflicts of Interest}

The authors declare no conflicts of interest regarding the publication of this paper.

\section{References}

Akçayir, M., \& Akçayir, G. (2017). Advantages and Challenges Associated with Augmented Reality for Education: A Systematic Review of the Literature. Educational Research Review, 20, 1-11. https://doi.org/10.1016/j.edurev.2016.11.002

Akçayir, M., Akçayir, G., Pektaş, H. M., \& Ocak, M. A. (2016). Augmented Reality in Science Laboratories: The Effects of Augmented Reality on University Students' Laboratory Skills and Attitudes toward Science Laboratories. Computers in Human Behavior, 57, 334-342. https://doi.org/10.1016/j.chb.2015.12.054

All, A., Plovie, B., Castellar, E. P. N., \& Looy, J. V. (2017). Pre-Test Influences on the Effectiveness of Digital-Game Based Learning: A Case Study of a Fire Safety Game. 
Computers \& Education, 114, 24-37. https://doi.org/10.1016/j.compedu.2017.05.018

Amin, D., \& Govilkar, S. (2015). Comparative Study of Augmented Reality SDK's. International Journal on Computational Sciences \& Applications, 5, 11-26. https://doi.org/10.5121/ijcsa.2015.5102

AURASMA (2017). Official Aurasma Web Page. https://www.aurasma.com

Azuma, R. (1997). A Survey of Augmented Reality. Presence: Teleoperators and Virtual Environments, 6, 355-385. https://doi.org/10.1162/pres.1997.6.4.355

Azuma, R., Baillot, Y., Behringer, R., Feiner, S., Julier, S., \& Macintyre, B. (2001). Recent Advances in Augmented Reality. IEEE Computer Graphics and Applications, 21, 34-47. https://doi.org/10.1109/38.963459

Bacca, J., Baldiris, S., Fabregat, R., Graf, S., \& Kinshuk (2014). Augmented Reality Trends in Education: A Systematic Review of Research and Applications. Educational Technology \& Society, 17, 133-149.

Becker, S. A., Cummins, M., Davis, A., Freeman, A., Giesinger, C. H., \& Ananthanarayanan, V. (2017). NMC Horizon Report: 2017 Higher Education Edition. Austin, TX: The New Media Consortium.

Botella, C., Breton-López, J., Quero, S., Baños, R. M., García-Palacios, A., Zaragoza, I., \& Alcaniz, M. (2011). Treating Cockroach Phobia Using a Serious Game on a Mobile Phone and Augmented Reality Exposure: A Single Case Study. Computers in Human Behavior, 27, 217-227. https://doi.org/10.1016/j.chb.2010.07.043

Branch, R. M. (2010). Instructional Design: The ADDIE Approach (203 p.). New York, Dordrecht, Heidelberg, London: Springer.

Bressler, D. M., \& Bodzin, A. M. (2013). A Mixed Methods Assessment of Students' Flow Experiences during a Mobile Augmented Reality Science Game. Journal of Computer Assisted Learning, 29, 505-517. https://doi.org/10.1111/jcal.12008

Bressler, D. M., \& Bodzin, A. M. (2016). Investigating Flow Experience and Scientific Practices during a Mobile Serious Educational Game. Journal of Science Education and Technology, 25, 795-805. https://doi.org/10.1007/s10956-016-9639-Z

Brooke, J. (1996). SUS-A Quick and Dirty Usability Scale. In P. W. Jordan, B. Thomas, B. A. Weerdmeester, \& I. L. McClelland (Eds.), Usability Evaluation in Industry (pp. 189-194). London: Taylor \& Francis.

Bruner, J. S. (1961). The Act of Discovery. Harvard Educational Review, 31, 21-32.

Caballero-Hernández, J. A., Palomo-Duarte, M., \& Dodero, J. M. (2017). Skill Assessment in Learning Experiences Based on Serious Games: A Systematic Mapping Study. Computers \& Education, 113, 42-60. https://doi.org/10.1016/j.compedu.2017.05.008

Cai, S., Wang, X., \& Chiang, F. K. (2014). A Case Study of Augmented Reality Simulation System Application in a Chemistry Course. Computers in Human Behavior, 37, 31-40. https://doi.org/10.1016/j.chb.2014.04.018

Calderón, A., \& Ruiz, M. (2015). A Systematic Literature Review on Serious Games Evaluation: An Application to Software Project Management. Computers \& Education, 87, 396-422. https://doi.org/10.1016/j.compedu.2015.07.011

Calderón, A., Ruiz, M., \& O’Connor, R. V. (2018). A Multivocal Literature Review on Serious Games for Software Process Standards Education. Computer Standards and Interfaces, 57, 36-48. https://doi.org/10.1016/j.csi.2017.11.003

Chang, H., Wu, H., \& Hsu, Y. (2013). Integrating a Mobile Augmented Reality Activity to Contextualize Student Learning of a Socioscientific Issue. British Journal of Educational Technology, 44, 95-99. https://doi.org/10.1111/j.1467-8535.2012.01379.x

Chang, K. E., Chang, C. T., Hou, H. T., Sung, Y. T., Chao, H. L., \& Lee, C. M. (2014). De- 
velopment and Behavioral Pattern Analysis of a Mobile Guide System with Augmented Reality for Painting Appreciation Instruction in an Art Museum. Computers \& Education, 71, 185-197. https://doi.org/10.1016/j.compedu.2013.09.022

Chang, S. C., \& Hwang, G. J. (2018) Impacts of an Augmented Reality-Based Flipped Learning Guiding Approach on Students' Scientific Project Performance and Perceptions. Computers \& Education, 125, 226-239.

https://doi.org/10.1016/j.compedu.2018.06.007

Chang, Y., Hou, H., Pan, C., Sung, Y., \& Chang, K. (2015). Apply an Augmented Reality in a Mobile Guidance to Increase Sense of Place for Heritage Places. Educational Technology \& Society, 18, 166-178.

Chao, K.-H. et al. (2016). Integration of Mobile AR Technology in Performance Assessment. Educational Technology \& Society, 19, 239-251.

Chatzopoulos, D., Bermejo, C., Huang, Z., \& Hui, P. (2017). Mobile Augmented Reality Survey: From Where We Are to Where We Go. IEEE Access, 5, 6917-6950. https://doi.org/10.1109/ACCESS.2017.2698164

Chen, C., \& Tsai, Y. (2012). Interactive Augmented Reality System for Enhancing Library Instruction in Elementary Schools. Computers \& Education, 59, 638-652. https://doi.org/10.1016/j.compedu.2012.03.001

Cheng, K. H. (2018). Parents' User Experiences of Augmented Reality Book Reading: Perceptions, Expectations, and Intentions. Educational Technology Research and Development, 67, 303-315.

Cheng, K. H., \& Tsai, C. C. (2014). Children and Parents' Reading of an Augmented Reality Picture Book: Analyses of Behavioral Patterns and Cognitive Attainment. Computers \& Education, 72, 302-312. https://doi.org/10.1016/j.compedu.2013.12.003

Cheng, K., \& Tsai, C. (2016). The Interaction of Child-Parent Shared Reading with an Augmented Reality (AR) Picture Book and Parents' Conceptions of AR Learning. British Journal of Educational Technology, 47, 203-222. https://doi.org/10.1111/bjet.12228

Chiang, T. H. C., Yang, S. J. H., \& Hwang, G. (2014a). An Augmented Reality-Based Mobile Learning System to Improve Students' Learning Achievements and Motivations in Natural Science Inquiry Activities. Educational Technology \& Society, 17, 352-365.

Chiang, T. H. C., Yang, S. J. H., \& Hwang, G. J. (2014b). Students' Online Interactive Patterns in Augmented Reality-Based Inquiry Activities. Computers \& Education, 78, 97-108. https://doi.org/10.1016/j.compedu.2014.05.006

Chittaro, L., \& Ranon, R. (2007). Web3D Technologies in Learning, Education and Training: Motivations, Issues, Opportunities. Computers \& Education, 49, 3-18. https://doi.org/10.1016/j.compedu.2005.06.002

Chiu, J. L., Dejaegherc, C. J., \& Chaob, J. (2015). The Effects of Augmented Virtual Science Laboratories on Middle School Students' Understanding of Gas Properties. Computers \& Education, 85, 59-73. https://doi.org/10.1016/j.compedu.2015.02.007

Chung, N., Han, H., \& Joun, Y. (2015). Tourists' Intention to Visit a Destination: The Role of Augmented Reality (AR) Application for a Heritage Site. Computers in Human Behavior, 50, 588-599. https://doi.org/10.1016/j.chb.2015.02.068

Clark, D. B., Tanner-Smith, E. E., \& Killingsworth, S. (2016). Digital Games, Design, and Learning: A Systematic Review and Meta-Analysis. Review of Educational Research, 86, 79-122. https://doi.org/10.3102/0034654315582065

Coimbra, T., Cardoso, T., \& Mateus, A. (2015). Augmented Reality: An Enhancer for Higher Education Students in Math's Learning? Procedia Computer Science, 67, 332-339.

Cubillo, I. N., Martin, S., Castro, M., \& Boticki, I. (2015). Preparing Augmented Reality 
Learning Content Should Be Easy: UNED ARLE-An Authoring Tool for Augmented Reality Learning Environments. Computer Applications in Engineering Education, 23, 778-789. https://doi.org/10.1002/cae.21650

Davis, F. D. (1989). Perceived Usefulness, Perceived Ease of Use, and User Acceptance of Information Technology. MIS Quarterly, 13, 319-340. https://doi.org/10.2307/249008

Delello, J. A. (2014). Insights from Pre-Service Teachers Using Science-Based Augmented Reality. Journal of Computers in Education, 1, 295-311.

https://doi.org/10.1007/s40692-014-0021-y

Dey, A., Billinghurst, M., Lindeman, R. W., \& Swan, J. E. (2018). A Systematic Review of 10 Years of Augmented Reality Usability Studies: 2005 to 2014. Frontiers in Robotics and AI, 5, 37. https://doi.org/10.3389/frobt.2018.00037

Diegmann, P., Schmidt-Kraepelin, M., Eynden, S., \& Basten, D. (2015). Benefits of Augmented Reality in Educational Environments-A Systematic Literature Review. In O. Thomas, \& F. Teuteberg (Eds.), Proceedings der 12th Internationalen Tagung Wirtschaftsinformatik (pp. 1542-1556). Osnabruck: AIS Electronic Library (AISeL).

Dillenbourg, P. (1999). Collaborative Learning: Cognitive and Computational Approaches. Advances in Learning and Instruction Series (246 p.). New York: Elsevier Science \& Technology Books.

Di-Serio, Á., Ibáñez, M. B., \& Kloos, C. D. (2013). Impact of an Augmented Reality System on Students' Motivation for a Visual Art Course. Computers \& Education, 68, 586-596. https://doi.org/10.1016/j.compedu.2012.03.002

Dunleavy, M., \& Dede, C. (2014). Augmented Reality Teaching and Learning. In J. M. Spector, M. D. Merrill, J. Elen, \& M. J. Bishop (Eds.), Handbook of Research on Educational Communications and Technology (4th ed., pp. 735-745). New York: Springer.

Dünser, A., Grasset, R., \& Billinghurst, M. (2008). A Survey of Evaluation Techniques Used in Augmented Reality Studies. Human Interface Technology Laboratory New Zealand, Technical Report TR-2008-02.

Echeverría, A., Améstica, M., Gil, F., Nussbaum, M., Barrios, E., \& Leclerc, S. (2012). Exploring Different Technological Platforms for Supporting Co-Located Collaborative Games in the Classroom. Computers in Human Behavior, 28, 1170-1177. https://doi.org/10.1016/j.chb.2012.01.027

Fenton, N. E., \& Pfleeger, S. L. (1998). Software Metrics: A Rigorous and Practical Approach (2nd ed., 617 p.). Boston, MA: PWS Pub. Co.

Fonseca, D., Martí, N., Redondo, E., Navarro, I., \& Sánchez, A. (2014). Relationship between Student Profile, Tool Use, Participation, and Academic Performance with the Use of Augmented Reality Technology for Visualized Architecture Models. Computers in Human Behavior, 31, 434-445. https://doi.org/10.1016/j.chb.2013.03.006

Fonseca, D., Valls, F., Redondo, E., \& Villagrasa, S. (2016). Informal Interactions in 3D Education: Citizenship Participation and Assessment of Virtual Urban Proposals. Computers in Human Behavior, 55, 504-518. https://doi.org/10.1016/j.chb.2015.05.032

Frank, J. A., \& Kapila, V. (2017). Mixed-Reality Learning Environments: Integrating Mobile Interfaces with Laboratory Test-Beds. Computers \& Education, 110, 88-104. https://doi.org/10.1016/j.compedu.2017.02.009

Freedman, D., Pisani, R., \& Purves, R. (2007). Statistics (4th ed.). New York: W. W. Norton \& Company.

Furió, D., González-Gancedo, S., Juan, M. C., Seguí, I., \& Rando, N. (2013a). Evaluation of Learning Outcomes Using an Educational iPhone Game vs. Traditional Game. Computers \& Education, 64, 1-23. https://doi.org/10.1016/j.compedu.2012.12.001

Furió, D., González-Gancedo, S., Juan, M., Seguí, I., \& Costa, M. (2013b). The Effects of 
the Size and Weight of a Mobile Device on an Educational Game. Computers \& Education, 64, 24-41.

Furió, D., Juan, M., Seguí, I., \& Vivó, R. (2015). Mobile Learning vs. Traditional Classroom Lessons: A Comparative Study. Journal of Computer Assisted Learning, 31, 189-201.

Giasiranis, S., \& Sofos, L. (2016). Production and Evaluation of Educational Material Using Augmented Reality for Teaching the Module of "Representation of the Information on Computers" in Junior High School. Creative Education, 7, 1270-1291. https://doi.org/10.4236/ce.2016.79134

Giasiranis, S., \& Sofos, L. (2017). Flow Experience and Educational Effectiveness of Teaching Informatics Using AR. Journal of Educational Technology \& Society, 20, 78-88.

Guazzaroni, G. (2013). Emotional Mapping of the Archaeologist Game. Computers in Human Behavior, 29, 335-344. https://doi.org/10.1016/j.chb.2012.06.008

Guillermo, O. E. P. (2016). Use of Virtual Labs Learning in Hydraulics and Fluid Mechanics in Engineering (162 p.). PhD Thesis, Porto Alegre: Federal University of Rio Grande do Sul.

Hainey, T., Connolly, T. M., Boyle, E. A., Wilson, A., \& Razak, A. (2016). A Systematic Literature Review of Games-Based Learning Empirical Evidence in Primary Education. Computers \& Education, 102, 202-223. https://doi.org/10.1016/j.compedu.2016.09.001

Hanafi, H. F., Said, C. S., Wahab, M. H., \& Samsuddin, K. (2017). Improving Students' Motivation in Learning ICT Course with the Use of a Mobile Augmented Reality Learning Environment. International Research and Innovation Summit, 226, Article ID: 012114. https://doi.org/10.1088/1757-899X/226/1/012114

Harley, J. M., Poitras, E. G., Jarrell, A., Duffy, M. C., \& Lajoie, S. P. (2016). Comparing Virtual and Location-Based Augmented Reality Mobile Learning: Emotions and Learning Outcomes. Educational Technology Research and Development, 64, 359-388. https://doi.org/10.1007/s11423-015-9420-7

Heradio, R., de la Torre, L., Galan, D., Cabrerizo, F. J., Herrera-Viedma, E., \& Dormido, S. (2016). Virtual and Remote Labs in Education: A Bibliometric Analysis. Computers \& Education, 98, 14-38. https://doi.org/10.1016/j.compedu.2016.03.010

Herpich, F., Guarese, R. L. M., \& Tarouco, L. M. R. (2017). A Comparative Analysis of Augmented Reality Frameworks Aimed at the Development of Educational Applications. Creative Education, 8, 1433-1451. https://doi.org/10.4236/ce.2017.89101

Ho, S. C., Hsieh, S. W., Sun, P. C., \& Chen, C. M. (2017). To Activate English Learning: Listen and Speak in Real Life Context with an AR Featured U-Learning System. Journal of Educational Technology \& Society, 20, 176-187.

Hsu, T. C. (2017). Learning English with Augmented Reality: Do Learning Styles Matter? Computers \& Education, 106, 137-149.

Huang, T. C., Chen, C. C., \& Chou, Y. W. (2016). Animating Eco-Education: To See, Feel, and Discover in an Augmented Reality-Based Experiential Learning Environment. Computers \& Education, 96, 72-82. https://doi.org/10.1016/j.compedu.2016.02.008

Hung, Y. H., Chen, C. H., \& Huang, S. W. (2017). Applying Augmented Reality to Enhance Learning: A Study of Different Teaching Materials. Journal of Computer Assisted Learning, 33, 252-266. https://doi.org/10.1111/jcal.12173

Hwang, G. J., Chang, S. C., Chen, P. Y., \& Chen, X. Y. (2018). Effects of Integrating an Active Learning-Promoting Mechanism into Location-Based Real-World Learning Environments on Students' Learning Performances and Behaviors. Educational Technology Research and Development, 66, 451-474. 
https://doi.org/10.1007/s11423-017-9567-5

Ibanez, M. B., Di-Serio, A., Villarán-Molina, D., \& Delgado-Kloos, C. (2016). Support for Augmented Reality Simulation Systems: The Effects of Scaffolding on Learning Outcomes and Behavior Patterns. IEEE Transactions on Learning Technologies, 9, 46-56. https://doi.org/10.1109/TLT.2015.2445761

International Standard Organization (ISO) (1998). ISO 9241-11 Ergonomic Requirements for Office Work with Visual Display Terminals (VDTs) Part 11: Guidance on Usability (22 p.). Technical Committee: ISO/TC 159/SC 4 Ergonomics of Human-System Interaction.

Jamali, S. S., Shiratuddin, M. F., Wong, K. W., \& Oskam, C. L. (2015). Utilising Mobile-Augmented Reality for Learning Human Anatomy. Procedia-Social and Behavioral Sciences, 197, 659-668. https://doi.org/10.1016/j.sbspro.2015.07.054

Jeamu, L., Kim, Y., \& Lee, Y. (2008). A Web-Based Program to Motivate Underachievers Learning Number Sense. International Journal of Instructional Media, 35, 185-194.

Jong, T., Linn, M. C., \& Zacharia, Z. C. (2013). Physical and Virtual Laboratories in Science and Engineering Education. Science, 340, 305-309.

Joo-Nagata, J., Abad, F. M., Giner, J. G.-B., \& García-Peñalvo, F. J. (2017). Augmented Reality and Pedestrian Navigation through Its Implementation in m-Learning and e-Learning: Evaluation of an Educational Program in Chile. Computers \& Education, 111, 1-17. https://doi.org/10.1016/j.compedu.2017.04.003

Kamarainen, A. M., Metcalf, S., Grotzer, T., Browne, A., Mazzuca, D., Tutwiler, M. S., \& Dede, C. (2013). EcoMOBILE: Integrating Augmented Reality and Probeware with Environmental Education Field Trips. Computers \& Education, 68, 545-556.

https://doi.org/10.1016/j.compedu.2013.02.018

Kitchenham, B., Pretorius, R., Budgen, D., Brereton, O. P., Turner, M., Niazi, M., \& Linkman, S. (2010). Systematic Literature Reviews in Software Engineering-A Tertiary Study. Information and Software Technology, 52, 792-805.

https://doi.org/10.1016/j.infsof.2010.03.006

Kose, U., Koc, D., \& Anil, S. (2013). An Augmented Reality Based Mobile Software to Support Learning Experiences in Computer Science Courses. Procedia Computer Science, 25, 370-374. https://doi.org/10.1016/j.procs.2013.11.045

Kysela, J., \& Štorková, P. (2015). Using Augmented Reality as a Medium for Teaching History and Tourism. Procedia-Social and Behavioral Sciences, 174, 926-931.

https://doi.org/10.1016/j.sbspro.2015.01.713

Laine, T. H., Nygren, E., Dirin, A., \& Suk, H. J. (2016). Science Spots AR: A Platform for Science Learning Games with Augmented Reality. Educational Technology Research and Development, 64, 507-531. https://doi.org/10.1007/s11423-015-9419-0

Lee, H., Parsons, D., Kwon, G., Kim, J., Petrova, K., Jeong, E., \& Ryu, H. (2016). Cooperation Begins: Encouraging Critical Thinking Skills through Cooperative Reciprocity Using a Mobile Learning Game. Computers \& Education, 97, 97-115.

https://doi.org/10.1016/j.compedu.2016.03.006

Lin, T. J., Duh, H. B. L., Li, N., Wang, H. Y., \& Tsai, C. C. (2013). An Investigation of Learners' Collaborative Knowledge Construction Performances and Behavior Patterns in an Augmented Reality Simulation System. Computers \& Education, 68, 314-321. https://doi.org/10.1016/j.compedu.2013.05.011

Lindgren, R., Tscholl, M., Wang, S., \& Johnson, E. (2016). Enhancing Learning and Engagement through Embodied Interaction within a Mixed Reality Simulation. Computers \& Education, 95, 174-187. https://doi.org/10.1016/j.compedu.2016.01.001 
Liou, H. H., Yang, S. J. H., Chen, S. Y., \& Tarng, W. (2017). The Influences of the 2D Image-Based Augmented Reality and Virtual Reality on Student Learning. Educational Technology \& Society, 20, 110-121.

Liou, W. K., Bhagat, K. K., \& Chang, C. Y. (2016). Beyond the Flipped Classroom: A Highly Interactive Cloud-Classroom (HIC) Embedded into Basic Materials Science Courses. Journal of Science Education and Technology, 25, 460-473.

https://doi.org/10.1007/s10956-016-9606-8

Lorenzin, M. P., Assumpção, C. M., \& Rabello, M. (2016). Metáforas Mecânicas: Uma proposta STEAM para o ensino de ciências. In 6 Congresso Pesquisa do Ensino educação e tecnologia: revisitando a sala de aula (pp. 1-14). São Paulo: CONPE.

Mahmoudi, M. T., Mojtahedi, S., \& Shams, S. (2017). AR-Based Value-Added Visualization of Infographic for Enhancing Learning Performance. Computer Applications in Engineering Education, 25, 1038-1052. https://doi.org/10.1002/cae.21853

Martín-Gutiérrez, J., Fabiani, P., Benesova, W., Meneses, M. D., \& Mora, C. E. (2015). Augmented Reality to Promote Collaborative and Autonomous Learning in Higher Education. Computers in Human Behavior, 51, 752-761. https://doi.org/10.1016/j.chb.2014.11.093

Mayer, R. E. (1997). Multimedia Learning: Are We Asking the Right Questions? Educational Psychologist, 32, 1-19. https://doi.org/10.1207/s15326985ep3201_1

Milgram, P., \& Kishino, F. (1994). Taxonomy of Mixed Reality Visual Displays. IEICE Transactions on Information and Systems, E77-D, 1321-1329.

Muñoz-Cristóbal, J. A., Gallego-Lema, V., Arribas-Cubero, H. F., Asensio-Pérez, J. I., \& Martínez-Monés, A. (2018). Game of Blazons Helping Teachers Conduct Learning Situations That Integrate Web Tools and Multiple Types of Augmented Reality. IEEE Transactions on Learning Technologies, 11, 506-519. https://doi.org/10.1109/TLT.2018.2808491

Muñoz-Cristóbal, J. A., Gallego-Lema, V., Arribas-Cubero, H. F., Martínez-Monés, A., \& Asensio-Pérez, J. I. (2017). Using Virtual Learning Environments in Bricolage Mode for Orchestrating Learning Situations across Physical and Virtual Spaces. Computers \& Education, 109, 233-252. https://doi.org/10.1016/j.compedu.2017.03.004

Navarro, E., \& van der Hoek, A. (2009). Multi-Site Evaluation of SimSE. In Proceedings of the 40th ACM Technical Symposium on Computer Science Education (pp. 326-330). New York: ACM. https://doi.org/10.1145/1508865.1508981

Nguyen, V. T., \& Dang, T. (2017). Setting up Virtual Reality and Augmented Reality Learning Environment in Unity. In IEEE International Symposium on Mixed and Augmented Reality (pp. 315-320). Piscataway, NJ: Institute of Electrical and Electronics Engineers. https://doi.org/10.1109/ISMAR-Adjunct.2017.97

O'Shea, P. M., \& Elliott, J. B. (2016). Augmented Reality in Education: An Exploration and Analysis of Currently Available Educational Apps. In C. Allison, L. Morgado, J. Pirker, D. Beck, J. Richter, \& C. Güetl (Eds.), Communications in Computer and Information Science (Immersive Learning Research Network: Second International Conference (iLRN)) (2nd ed., pp. 147-159). Santa Barbara, CA: Springer International Publishing. https://doi.org/10.1007/978-3-319-41769-1_12

Palmarini, R., Erkoyuncu, J. A., Roy, R., \& Torabmostaedi, H. (2018). A Systematic Review of Augmented Reality Applications in Maintenance. Robotics and Computer-Integrated Manufacturing, 49, 215-228. https://doi.org/10.1016/j.rcim.2017.06.002

Pérez-Sanagustín, M., Hernández-Leo, D., Santos, P., Kloos, C. D., \& Blat, J. (2014). Augmenting Reality and Formality of Informal and Non-Formal Settings to Enhance Blended Learning. IEEE Transactions on Learning Technologies, 7, 118-131. 
https://doi.org/10.1109/TLT.2014.2312719

Petri, G., \& Gresse von Wangenheim, C. (2017). How Games for Computing Education Are Evaluated? A Systematic Literature Review. Computers \& Education, 107, 68-90. https://doi.org/10.1016/j.compedu.2017.01.004

Potkonjak, V., Gardner, M., Callaghan, V., Mattila, P., Guetl, C., Petrovic, V. M., \& Jovanovic, K. (2016). Virtual Laboratories for Education in Science, Technology, and Engineering: A Review. Computers \& Education, 95, 309-327. https://doi.org/10.1016/j.compedu.2016.02.002

Quintero, E., Salinas, P., González-Mendívil, E., \& Ramírez, H. (2015). Augmented Reality app for Calculus: A Proposal for the Development of Spatial Visualization. Procedia Computer Science, 75, 301-305. https://doi.org/10.1016/j.procs.2015.12.251

Radziwill, N. M., Benton, M. C., \& Moellers, C. (2015). From STEM to STEAM: Reframing What It Means to Learn. The STEAM Journal, 2, 3. https://doi.org/10.5642/steam.20150201.3

Rameau, F., Ha, H., Joo, K., Choi, J., Park, K., \& Kweon, I. S. (2016). A Real-Time Augmented Reality System to See-Through Cars. IEEE Transactions on Visualization and Computer Graphics, 22, 2395-2404. https://doi.org/10.1109/TVCG.2016.2593768

Rautenbach, V., Coetzee, S., \& Jooste, D. (2016). Results of an Evaluation of Augmented Reality Mobile Development Frameworks for Addresses in Augmented Reality. Spatial Information Research, 24, 211-223. https://doi.org/10.1007/s41324-016-0022-1

Reyes, A. M., Villegas, O. O. V., Bojórquez, E. M., Sánchez, V. G. C., \& Nandayapa, M. (2016). A Mobile Augmented Reality System to Support Machinery Operations in Scholar Environments. Computer Applications in Engineering Education, 24, 967-981. https://doi.org/10.1002/cae.21772

Reyes-Aviles, F., \& Aviles-Cruz, C. (2018) Handheld Augmented Reality System for Resistive Electric Circuits Understanding for Undergraduate Students. Computer Applications in Engineering Education, 26, 602-616. https://doi.org/10.1002/cae.21912

Rodriguez-Gil, L., García-Zubia, J., Orduña, P., \& López-de-Ipiña, D. (2016). Towards New Multiplatform Hybrid Online Laboratory Models. IEEE Transactions on Learning Technologies, 10, 318-330. https://doi.org/10.1109/TLT.2016.2591953

Saidin, N. F., Halim, N. D. A., \& Yahaya, N. (2015). A Review of Research on Augmented Reality in Education: Advantages and Applications. International Education Studies, 8, 1-8. https://doi.org/10.5539/ies.v8n13p1

Santos, M. E. C., Chen, A., Taketomi, T., Yamamoto, G., Miyazaki, J., \& Kato, H. (2014b). Augmented Reality Learning Experiences: Survey of Prototype Design and Evaluation. IEEE Transactions on Learning Technologies, 7, 38-56. https://doi.org/10.1109/TLT.2013.37

Santos, M. E. C., Ty, J. F., Luebke, A. in W., Rodrigo, M. M. T., Taketomi, T., Yamamoto, G., Sandor, C., \& Kato, H. (2014a). Authoring Augmented Reality as Situated Multimedia. In Proceedings of the 22nd International Conference on Computers in Education (pp. 554-559). Japan: Asia-Pacific Society for Computers in Education.

Schmitz, B., Klemke, R., Walhout, J., \& Specht, M. (2015). Attuning a Mobile Simulation Game for School Children Using a Design-Based Research Approach. Computers \& Education, 81, 35-48. https://doi.org/10.1016/j.compedu.2014.09.001

Schneider, B., \& Blikstein, P. (2018). Tangible User Interfaces and Contrasting Cases as a Preparation for Future Learning. Journal of Science Education and Technology, 27, 369-384. https://doi.org/10.1007/s10956-018-9730-8

Social Compare (2017). Official Social Compare Web Page. 
http://socialcompare.com/en/comparison/augmented-reality-sdks

Sommerauer, P., \& Müller, O. (2014). Augmented Reality in Informal Learning Environments: A Field Experiment in a Mathematics Exhibition. Computers \& Education, 79, 59-68. https://doi.org/10.1016/j.compedu.2014.07.013

Specht, M., Ternier, S., \& Greller, W. (2011). Mobile Augmented Reality for Learning: A Case Study. Journal of the Research Center for Educational Technology, 7, 117-127.

Theall, M. (1999). New Directions for Theory and Research on Teaching: A Review of the Past Twenty Years. New Directions for Teaching and Learning, 80, 29-52. https://doi.org/10.1002/tl.8002

Vuforia (2018). Official Vuforia Web Page. https://www.vuforia.com

Wang, M., Callaghan, V., Bernhardt, J., White, K., \& Peña-Rios, A. (2017). Augmented Reality in Education and Training: Pedagogical Approaches and Illustrative Case Studies. Journal of Ambient Intelligence and Humanized Computing, 9, 1391-1402.

Wang, Y. H. (2017a). Exploring the Effectiveness of Integrating Augmented Reality-Based Materials to Support Writing Activities. Computers \& Education, 113, 162-176. https://doi.org/10.1016/j.compedu.2017.04.013

Wang, Y. H. (2017b). Using Augmented Reality to Support a Software Editing Course for College Students. Journal of Computer Assisted Learning, 33, 532-546. https://doi.org/10.1111/jcal.12199

Wang, Y. H., Duh, H. B. L., Li, N., Lin, T. J., \& Tsai, C. C. (2014). An Investigation of University Students' Collaborative Inquiry Learning Behaviors in an Augmented Reality Simulation and a Traditional Simulation. Journal of Science Education and Technology, 23, 682-691. https://doi.org/10.1007/s10956-014-9494-8

Wikitude (2018). Official Wikitude Web Page. https://www.wikitude.com

Wohlin, C., Runeson, P., Höst, M., Ohlsson, M. C., Regnell, B., \& Wesslén, A. (2012). Experimentation in Software Engineering (236 p.). Berlin Heidelberg: Springer-Verlag.

Yang, M. T., \& Liao, W. C. (2014). Computer-Assisted Culture Learning in an Online Augmented Reality Environment Based on Free-Hand Gesture Interaction. IEEE Transactions on Learning Technologies, 7, 107-117. https://doi.org/10.1109/TLT.2014.2307297

Yen, J., Tsai, C., \& Wu, M. (2013). Augmented Reality in the Higher Education: Students' Science Concept Learning and Academic Achievement in Astronomy. Procedia-Social and Behavioral Science, 103, 165-173. https://doi.org/10.1016/j.sbspro.2013.10.322

Yilmaz, R. M. (2016). Educational Magic Toys Developed with Augmented Reality Technology for Early Childhood Education. Computers in Human Behavior, 54, 240-248. https://doi.org/10.1016/j.chb.2015.07.040

Yoon, S., Anderson, E., Lin, J., \& Elinich, K. (2017). How Augmented Reality Enables Conceptual Understanding of Challenging Science Content. Educational Technology and Society, 20, 156-168.

Zarzuela, M. M., Pernas, F. J. D., Martínez, L. B., Ortega, D. G., \& Rodríguez, M. A. (2013). Mobile Serious Game Using Augmented Reality for Supporting Children's Learning about Animals. Procedia Computer Science, 25, 375-381. https://doi.org/10.1016/j.procs.2013.11.046

Zhang, J., Ogan, A., Liu, T. C., Sung, Y. T., \& Chang, K. E. (2016). The Influence of Using Augmented Reality on Textbook Support for Learners of Different Learning Styles. In IEEE International Symposium on Mixed and Augmented Reality (pp. 107-114). Piscataway, NJ: Institute of Electrical and Electronics Engineers. 
https://doi.org/10.1109/ISMAR.2016.26

Zhang, J., Sung, Y. T., Hou, H. T., \& Chang, K. E. (2014). The Development and Evaluation of an Augmented Reality-Based Armillary Sphere for Astronomical Observation Instruction. Computers \& Education, 73, 178-188.

https://doi.org/10.1016/j.compedu.2014.01.003

Zhu, E., Hadadgar, A., Masiello, I., \& Zary, N. (2014). Augmented Reality in Healthcare Education: An Integrative Review. PeerJ, 2, e469. https://doi.org/10.7717/peerj.469

\section{Supplementary Material}

Link: http://dx.doi.org/10.17632/gv34bvthdx.1. 